\title{
Waveform modeling of the slab beneath Japan
}

\author{
Min Chen, ${ }^{1}$ Jeroen Tromp, ${ }^{1}$ Don Helmberger, ${ }^{1}$ and Hiroo Kanamori ${ }^{1}$ \\ Received 16 March 2006; revised 28 August 2006; accepted 10 October 2006; published 20 February 2007.
}

[1] The tomographic $\mathrm{P}$ wave model for the Japan subduction zone derived by Zhao et al. (1994) has two very striking features: a slab about $90 \mathrm{~km}$ thick with $\mathrm{P}$ wave velocities 3 $6 \%$ higher than the surrounding mantle and a mantle wedge with $-6 \%$ low-velocity anomalies. We study three-component seismograms from more than 600 Hi-net stations produced by two earthquakes which occurred in the downgoing Pacific Plate at depths greater than $400 \mathrm{~km}$. We simulate body wave propagation in the three-dimensional (3-D) P wave model using 2-D finite difference (FDM) and 3-D spectral element (SEM) methods. As measured by cross correlation between synthetics and data, the $\mathrm{P}$ wave model typically explains about half of the traveltime anomaly and some of the waveform complexity but fails to predict the extended SH wave train. In this study we take advantage of the densely distributed Hi-net stations and use 2-D FDM modeling to simulate the P-SV and $\mathrm{SH}$ waveforms. Our 2-D model suggests that a thin, elongated low-velocity zone exists atop the slab, extending down to a depth of $300 \mathrm{~km}$ with an S wave velocity reduction of $14 \%$ if a thickness of $20 \mathrm{~km}$ is assumed. Further, 3-D SEM simulations confirm that this model explains a strong secondary arrival which cannot easily be imaged with standard tomographic techniques. The low-velocity layer could explain the relatively weak coupling associated with most subduction zones at shallow depths $(<50 \mathrm{~km})$, generally involving abundant volcanic activity and silent earthquakes, and it may also help to further our understanding of the water-related phase transition of ultramafic rocks, and the nature of seismicity at intermediate depths $(\sim 70-300 \mathrm{~km})$.

Citation: Chen, M., J. Tromp, D. Helmberger, and H. Kanamori (2007), Waveform modeling of the slab beneath Japan, J. Geophys. Res., 112, B02305, doi:10.1029/2006JB004394.

\section{Introduction}

[2] Subduction zones represent some of the most heterogeneous regions in Earth's upper mantle in terms of seismic velocities. A great deal of tectonic activity, such as earthquakes, silent slip events, and volcanic eruptions, occurs in subduction zones due to dehydration of the slab and the associated melting inside the mantle wedge.

[3] Detailed three-dimensional (3-D) tomographic $\mathrm{P}$ wave studies of the Japanese subduction zone have been conducted on both regional and global scales by Zhao and Hasegawa [1993], Zhao et al. [1994], and Zhao [2001]. The tomographic models on both scales exhibit similar gross $\mathrm{P}$ wave heterogeneity. The $\mathrm{P}$ wave velocity is higher inside the slab and lower in the wedge compared to the ambient mantle (Figure 1). The imaged anomalies are well correlated with seismic and volcanic activities. However, the regional and global models also exhibit significant differences (Figure 1b): the regional model has a sharp $\mathrm{P}$ velocity contrast across the top of the slab, while the contrast in the global model is weaker and smoother; the regional model has no high-velocity anomaly inside the transition

\footnotetext{
${ }^{1}$ Seismological Laboratory, California Institute of Technology, Pasadena, California, USA.

Copyright 2007 by the American Geophysical Union. 0148-0227/07/2006JB004394\$09.00
}

zone due to a lack of depth resolution below $500 \mathrm{~km}$, whereas the global model has a high-velocity slab-shaped anomaly inside the transition zone (410-660 km), which was resolved by traveltime data from teleseismic events. In order to better explain body wave traveltimes and waveforms, it is necessary to incorporate the observed global features into the regional model, and to determine the correct amplitude of the $\mathrm{P}$ velocity anomalies inside the slab and in the mantle wedge.

[4] There are a few inherent drawbacks of the regional model [Zhao et al., 1994] in terms of explaining the data from local deep earthquakes. The Japan University Seismic Network (216 stations) was used in the inversion, but due to a lack of local earthquakes at depths greater than $500 \mathrm{~km}$, the array aperture is insufficient to resolve seismic velocity structure below depths of $\sim 400 \mathrm{~km}$. Furthermore, the starting model for the inversion by Zhao et al. [1994] contains a preconstrained slab and the traveltimes of S-to$\mathrm{P}$ and P-to-S converted phases (at the upper boundary of the slab) were used to provide better constraints on the velocity contrast across the slab's upper surface. These converted phases, however, do not provide any constraint on a possible sharp negative velocity jump. Finally, waveform distortions caused by sharp structures are not included in the tomographic inversion. These waveform perturbations consist of multiple interfering arrivals, resulting in distorted and widened arrivals. These features are addressed in this article by modifying the regional model. 
(a)

\section{Horizontal Cross-Section}

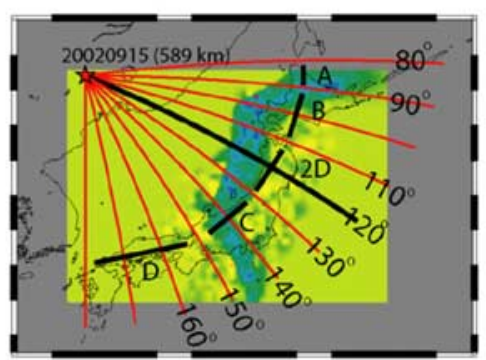

Depth $=250 \mathrm{~km}$

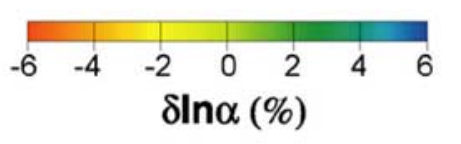

(b)

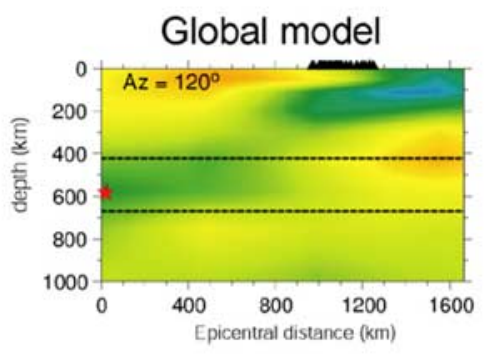

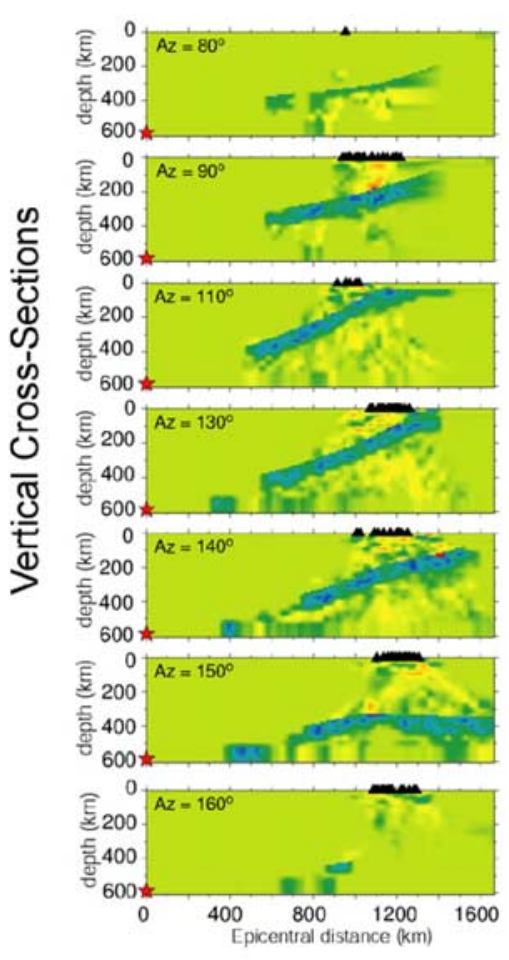

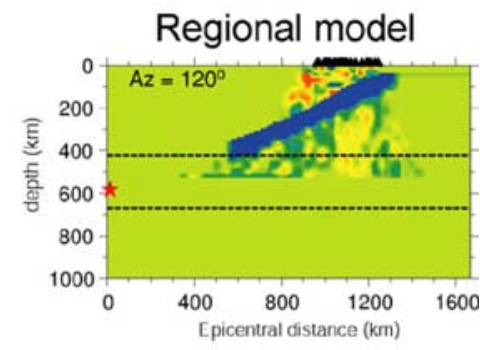

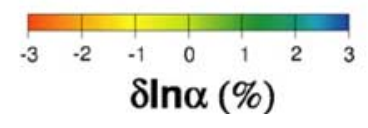

Figure 1. Cross sections through the regional and global tomographic $\mathrm{P}$ wave models derived by Zhao et al. [1994] and Zhao [2001]. Colors indicate P wave velocity anomalies relative to 1-D reference Earth model IASPEI91 [Kennett and Engdahl, 1991]. The slab is delineated by the blue colors (positive anomalies). The red star indicates the location of event 20020915 (depth $589 \mathrm{~km}$ ), and the stations along each profile are marked by black triangles. (a) Regional model [Zhao et al., 1994]. The horizontal cross section in the top left shows the $\mathrm{P}$ wave anomalies at a depth of $250 \mathrm{~km}$. The red lines roughly indicate the positions of the vertical cross sections in the top right. A, B, 2D, C, and D label five corridors with distinct slab geometries. Corridor A $\left(80-90^{\circ}\right)$, flattened slab. Corridors B $\left(90-110^{\circ}\right)$ and $\mathrm{C}\left(130-150^{\circ}\right)$, the bending edges of the slab. Corridor $2 \mathrm{D}\left(110-130^{\circ}\right)$, steepened slab with almost constant slope. Corridor D $\left(>160^{\circ}\right)$, the nonslab region. (b) Comparison between the global and regional $\mathrm{P}$ wave models. The two dashed lines indicate the $410 \mathrm{~km}$ and $660 \mathrm{~km}$ discontinuities, respectively. The cross sections are both along the black line in the top left map with a source station azimuth of $120^{\circ}$. Note that there is a positive (blue) anomaly inside the transition zone in the global model, but not in the regional model.

[5] It has long been observed that sharp structures have profound effects on waveforms, and that such waveform complexity can be used as an independent constraint on slab structure. There have been a few attempts to use 2-D and 3-D forward modeling to investigate the effects of slab geometry and heterogeneity on waveforms [Zhou and Chen,
1995; Vidale, 1987; Igel et al., 2002]. Some preliminary results based upon broadband sparse data coverage were obtained for slabs in other subduction zones, such as the slabs beneath North America [Vidale and Garcia-Gonzalez, 1988] and Kuril-Kamchatka [Cormier, 1989]. Recent work on guided waves in the subduction zone beneath Chile and 


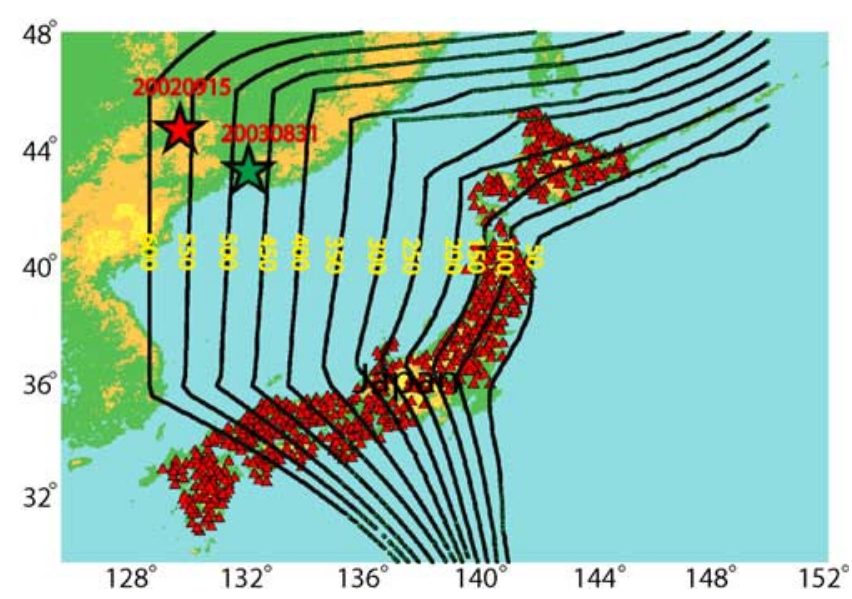

Figure 2. Map view of the study area. Hi-net stations are indicated by red triangles and contours of the upper boundary of the Pacific plate are indicated by black lines with a $50 \mathrm{~km}$ contour interval. The location of event 20020915 is marked by the red star, and event 20030831 is indicated by the green star.

Peru by Martin et al. [2003, 2005] include detailed investigations of a low-velocity layer on top of the slab. Furthermore, data from the Japanese K-NET and KiK-net strong motion instruments and the FREESIA broadband station was used by Furumura and Kennett [2005] to investigate waveform dispersion caused by elongated scatterers in the slab beneath Japan. In general, the waveform dispersion recorded at broadband stations $(0.25-18 \mathrm{~Hz})$ is often explained in terms of a low-velocity layer with a thickness less than $10 \mathrm{~km}$ and a $\mathrm{P}$ wave velocity reduction of $7 \%$, based upon Fourier spectral analysis and approximate $\mathrm{P}$ waveform comparison between data and synthetics.
[6] In this study, we take advantage of the dense and wide coverage of the Japanese Hi-net array, which is a highsensitivity network consisting of more than 600 borehole three-component, short-period (1 s) seismographs (Figure 2). Because the Hi-net instruments record only signals within a relatively narrow frequency band $(0.1-2 \mathrm{~Hz})$, waveform dispersion effects observed in this data set are not as prominent as in previous studies [Martin et al., 2003, 2005; Furumura and Kennett, 2005]. Our focus is on explaining strong secondary $\mathrm{S}$ arrivals. We use waveforms varying at the scale of tens of kilometers as additional constraints on slab structure, and present waveform modeling results using the 2-D finite difference method (FDM) by Vidale et al. [1985] and the 3-D spectral element method (SEM) by Komatitsch and Tromp [2002a, 2002b].

[7] We begin with a brief review of the numerical methods and related grids used in this study. This is followed by an assessment of how well the tomographic models developed by Zhao predict the observed $\mathrm{P}$ and $\mathrm{S}$ waves both in terms of timing and waveforms for a simple deep source. The SH waveforms for one particular 2-D corridor are most suitable for further analysis of slab structure, a subject which is addressed at length in the remaining sections.

\section{Numerical Simulations}

[8] In this section we introduce the grids used in the FDM and SEM simulations of seismic wave propagation in the regional and global $\mathrm{P}$ wave models [Zhao et al., 1994; Zhao, 2001]. The lateral domain for the regional model is $32-45^{\circ} \mathrm{N}$ and $130-145^{\circ} \mathrm{E}$, with a depth extent from the surface to $500 \mathrm{~km}$. The model properties outside this region are determined by the 1-D IASPEI91 model [Kennett and Engdahl, 1991]. The 3-D S wave models are obtained from

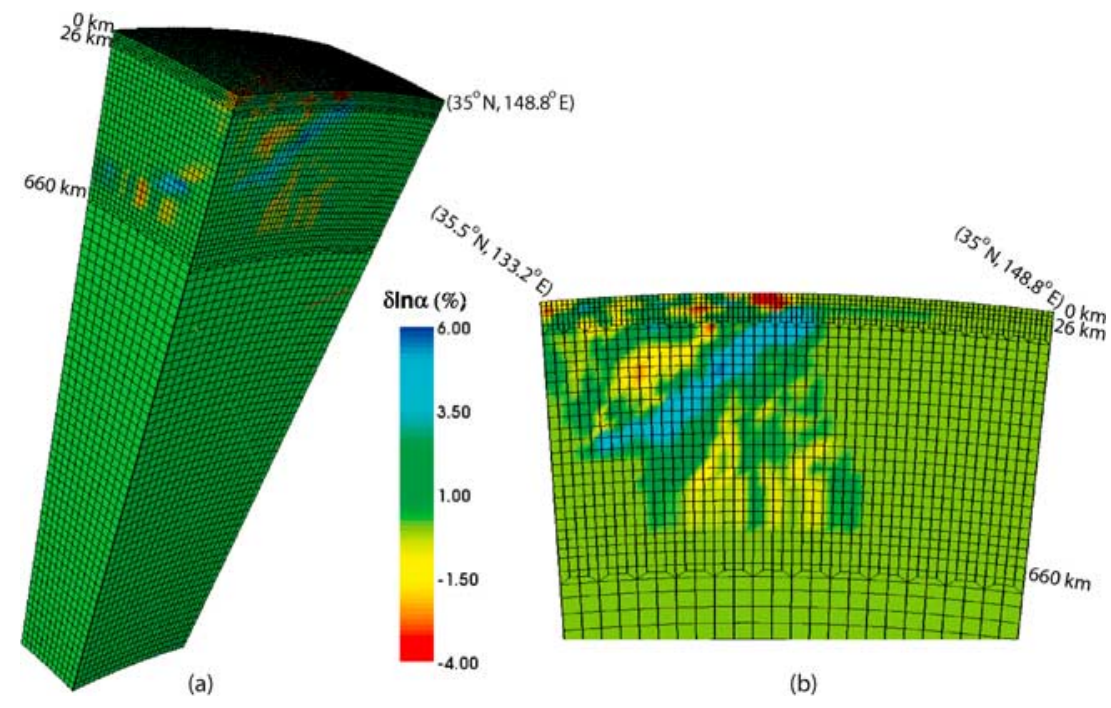

Figure 3. The 3-D spectral element mesh. $\mathrm{P}$ wave velocity anomalies from the regional tomographic model [Zhao et al., 1994] are superimposed on the mesh. For parallel computing purposes, the one-chunk SEM simulation is subdivided in terms of 25 slices. The center of the chunk is at $\left(38.5^{\circ} \mathrm{N}, 137.5^{\circ} \mathrm{E}\right)$, and the lateral dimensions are $30^{\circ} \times 30^{\circ}$. (a) Full view of two neighboring slices. (b) Close-up view of the upper mantle mesh. Note that the element size in the crust (top layer) is $15 \mathrm{~km} \times 15 \mathrm{~km}$ and that the size of the spectral elements is doubled in the upper mantle. The velocity variation is captured by five grid points in each direction of the elements [Komatitsch and Tromp, 2002a, 2002b]. 
(a)

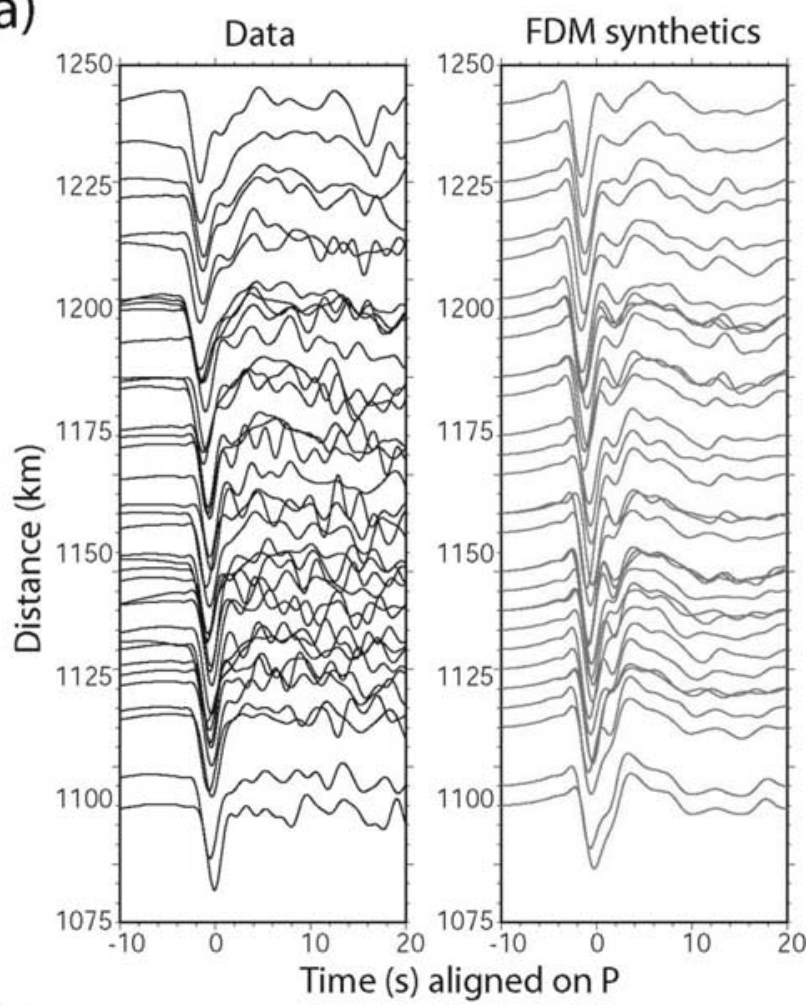

(b)

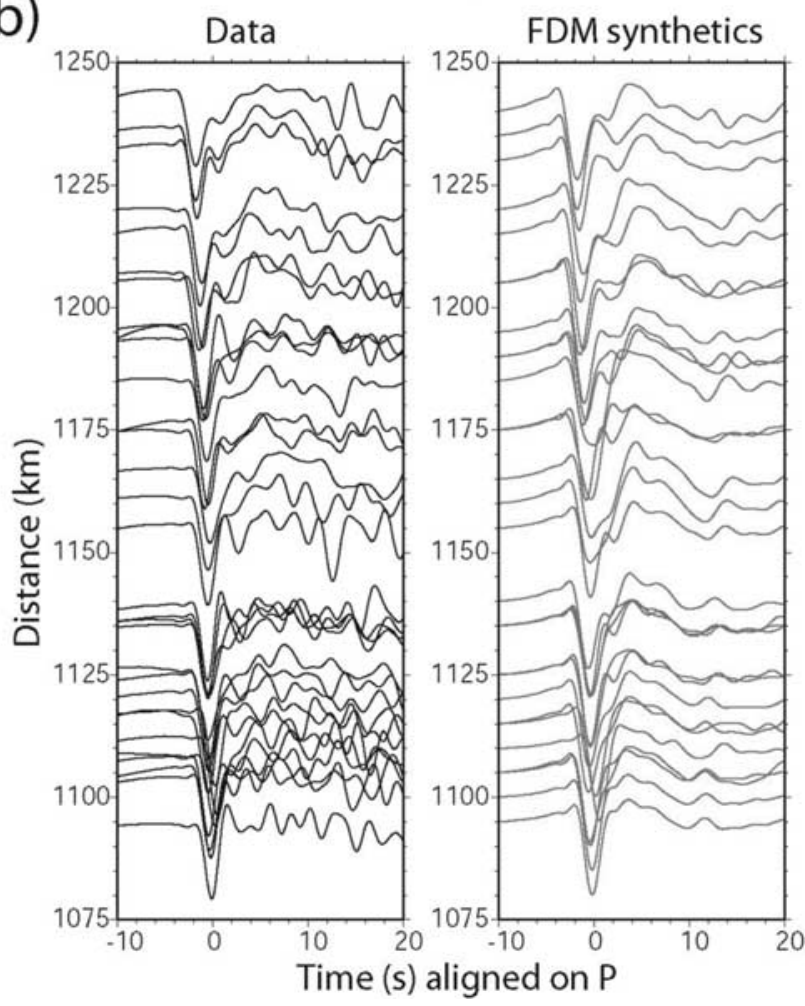

Figure 4. Waveform comparison between data (event 20020915) and 2-D FDM synthetics calculated for the regional model [Zhao et al., 1994]. Data are aligned on the direct $\mathrm{P}$ wave based upon 1-D reference model IASPEI91, and synthetics are aligned with the data using the time shifts shown in Figure 5c. (a) Distance profile in the azimuthal range $120-130^{\circ}$. (b) Distance profile in the azimuthal range $130-140^{\circ}$. the $\mathrm{P}$ velocity models using a scaling factor $f=\delta \ln \beta / \delta \ln$ $\alpha=1.5-2.5$, where $\beta$ denotes the shear wave velocity and $\alpha$ the compressional wave velocity. $\delta \ln \alpha$ and $\delta \ln \beta$ refer to the fractional velocity perturbations with respect to $1-\mathrm{D}$ IASPEI91 model. This range of scaling factors is representative of upper mantle tomography. The purpose of the 2-D FDM and 3-D SEM simulations is to assess the quality of the regional and global models by comparing data and synthetics in terms of both traveltimes and waveforms.

\subsection{FDM Simulations}

[9] The FDM simulations are carried out by simulating the P-SV and SH systems separately for each model. The 2-D models are 2-D slices which are obtained from the 3-D $\mathrm{P}$ model at source azimuths from $80^{\circ}$ to $180^{\circ}$ at $2^{\circ}$ intervals. For each slice, the 2-D model domain is $1200 \mathrm{~km}$ deep and $1800 \mathrm{~km}$ wide. The grid size throughout the entire domain is $2 \mathrm{~km} \times 2 \mathrm{~km}$. To confirm that this grid has the appropriate resolution, we did a few simulations at twice the resolution. For the periods of interest, this resulted in essentially the same synthetic seismograms. We placed the source $200 \mathrm{~km}$ from the left boundary and $600 \mathrm{~km}$ above the bottom boundary in order to avoid artificial reflections. The frequency contents of the FDM synthetics is $1 \mathrm{~Hz}$ and lower. The scheme for generating point source seismograms for shear dislocations using 2-D numerical methods is discussed by Helmberger and Vidale [1988]. It is based on expanding the complete 3-D solution in asymptotic form and separating the motions into the SH and P-SV systems. This analytical Cagniard-de Hoop method is used to derive closed form expressions appropriate for 2-D FDM source excitations. Synthetics generated by this method are benchmarked in the above mentioned study.

\subsection{SEM Simulations}

[10] For the SEM simulations we use the implementation of Komatitsch and Tromp [2002a, 2002b]. In our study we use only one of the six "cubed sphere" chunks that constitute the entire globe, with absorbing boundary conditions at the artificial edges of the domain. Compared to the full globe, this approach significantly reduces the memory and CPU requirements and allows for a much denser mesh in the modeling region. On 25 processors of a modern PC cluster (CITerra, 3.2 GHz Intel Xeon, http:// citerra.gps.caltech.edu/wiki/Public/Technology), this one chunk version SEM code can calculate synthetics accurate at periods of $\sim 6 \mathrm{~s}$ and longer in 3.5 hours for an $8.0 \mathrm{~min}$ record length. The model implementation and mesh configuration are shown in Figure 3; for clarity, only 2 of the 25 mesh slices are displayed. Elements in the upper mantle mesh have dimensions of $30 \mathrm{~km} \times 30 \mathrm{~km}$, which is twice as big as the elements in the crust. The doubling of element size with depth maintains a relatively similar number of grid points per wavelength. A polynomial degree 4 interpolation is used to capture the velocity variations within the spectral elements, and therefore the grid spacing is $\sim 7 \mathrm{~km}$ in the upper mantle and $\sim 3.5 \mathrm{~km}$ in the crust. We did a few SEM runs for a mesh with twice this resolution, i.e., a grid spacing of $\sim 3.5 \mathrm{~km}$ in the upper mantle and $\sim 1.75 \mathrm{~km}$ in the crust, and confirmed that at periods of $\sim 6 \mathrm{~s}$ and longer this mesh leads to the same synthetic seismograms as the 
coarser mesh, indicating that the coarser mesh accurately resolves the waves of interest.

\section{Data Selection and Model Testing}

[11] Hi-net waveform data from two deep earthquakes with relatively simple sources were chosen for this study: event 20020915 (location: $44.77^{\circ} \mathrm{N}, 130.04^{\circ} \mathrm{E}, 589 \mathrm{~km}$; fault plane 1: strike $204^{\circ}$, dip $85^{\circ}$, rake $72^{\circ}$; fault plane 2 : strike $98^{\circ}$, dip $19^{\circ}$, rake $\left.163^{\circ} ; M_{w}=6.4\right)$ and event 20030831 (location: $43.38^{\circ} \mathrm{N}, 132.37^{\circ} \mathrm{E}$, depth: $492 \mathrm{~km}$; fault plane 1: strike $77^{\circ}$, dip $45^{\circ}$, rake $-179^{\circ}$; fault plane 2: strike $346^{\circ}$, dip $89^{\circ}$, rake $-45^{\circ} ; M_{w}=6.1$ ) both are shown in Figure 2. The source locations and focal mechanisms are determined by the Harvard centroid moment tensor (CMT) solutions. We use the deeper event with better
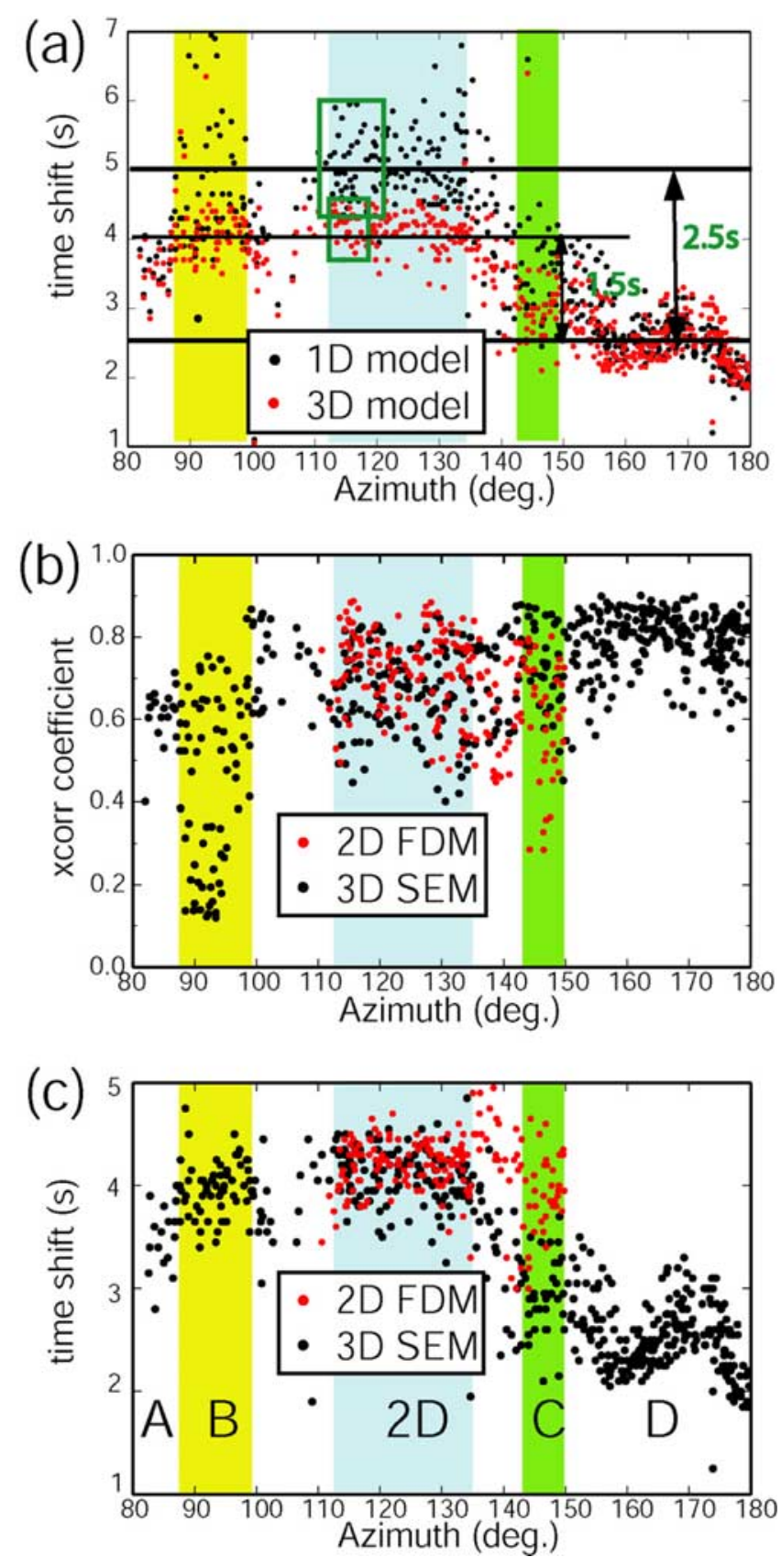

coverage to develop the model, and validate this model by successfully predicting the waveforms for the other event.

[12] We start by comparing the data with simulations based on the tomographic models developed by Zhao et al. [1994] and discussed earlier (Figure 1). In these initial simulations we grid the regional $\mathrm{P}$ wave model [Zhao et al., 1994] and experiment with four different $S$ wave models. Three $\mathrm{S}$ models are obtained by scaling the shear velocity $\beta$ to the compressional velocity $\alpha$ based upon overall scaling factors $f=\delta \ln \beta / \delta \ln \alpha=1.5,2.0$, and 2.5 , respectively. A fourth $\mathrm{S}$ model is obtained by using a scaling factor $f=2.0$ for the slab but a scaling factor of zero for the mantle wedge (i.e., no negative $\beta$ anomalies).

[13] Data and synthetics for all available Hi-net stations are band-pass-filtered between $1 \mathrm{~s}$ and $29 \mathrm{~s}$ for the FDM simulations and between $6 \mathrm{~s}$ and $29 \mathrm{~s}$ for the SEM simulations. For each component at every station, data and synthetic seismograms are cross-correlated in time windows centered on the predicted $\mathrm{P}$ or $\mathrm{S}$ arrivals relative to the 1-D IASPEI91 model. Cross correlations for P waves are conducted in a time window starting $10 \mathrm{~s}$ before and ending $20 \mathrm{~s}$ after the $\mathrm{P}$ arrival predicted by IASPEI91. For $\mathrm{S}$ waves, the time window is centered on the predicted IASPEI91 $\mathrm{S}$ arrival with a $30 \mathrm{~s}$ half window width. The time windows are chosen to be just wide enough to include the direct $\mathrm{P}$ and $\mathrm{S}$ arrivals, whose peak amplitudes are essential in determining the final cross-correlation results.

\subsection{P Waves}

[14] An example of P wave data and 2-D FDM synthetics for the regional model is displayed in Figure 4. The source time function is taken from stations at large azimuths (greater than $175^{\circ}$, Figure 1), where the slab is not sampled by the wavefield. These records are simple and similar to the observed $\mathrm{P}$ waves toward the bottom of the record sections shown in Figure 4. The more distant stations are closer to the slab (see Figure 1) and display complexity associated with the development of a secondary arrival.

Figure 5. Cross-correlation traveltime anomalies between data and 3-D SEM synthetics for $\mathrm{P}$ waves (event 20020915). Azimuthal windows A, B (yellow), 2D (light blue), $\mathrm{C}$ (green) and $\mathrm{D}$, labeled in the bottom panel, correspond to the corridors indicated in Figure 1a. (a) Comparison of cross-correlation traveltime anomalies between the data and 3-D SEM synthetics for the 1-D model (IASPEI91, black dots) and Zhao et al.'s [1994] regional P wave model (red dots). The black lines indicate average time shifts for all stations in regions with a slab (corridor $2 \mathrm{D}$ ), or the no-slab region (corridor D), and the traveltime anomaly is indicated by this azimuthal time shift offset. The 3 -D regional tomographic model shown in Figure $1 \mathrm{~b}$ (right) reduces the traveltime anomalies by almost half (from an average of $2.5 \mathrm{~s}$ to an average of $1.5 \mathrm{~s}$ ) compared to the 1-D model. The model also reduces the scatter in the traveltime anomalies by half for stations in the azimuthal range 110 $120^{\circ}$, as denoted by the green boxes. (b, c) Comparison of cross-correlation coefficients (Figure $5 \mathrm{~b}$ ) and traveltime anomalies (Figure 5c) between data and FDM (red dots) and SEM (black dots) synthetics calculated for the regional model. 

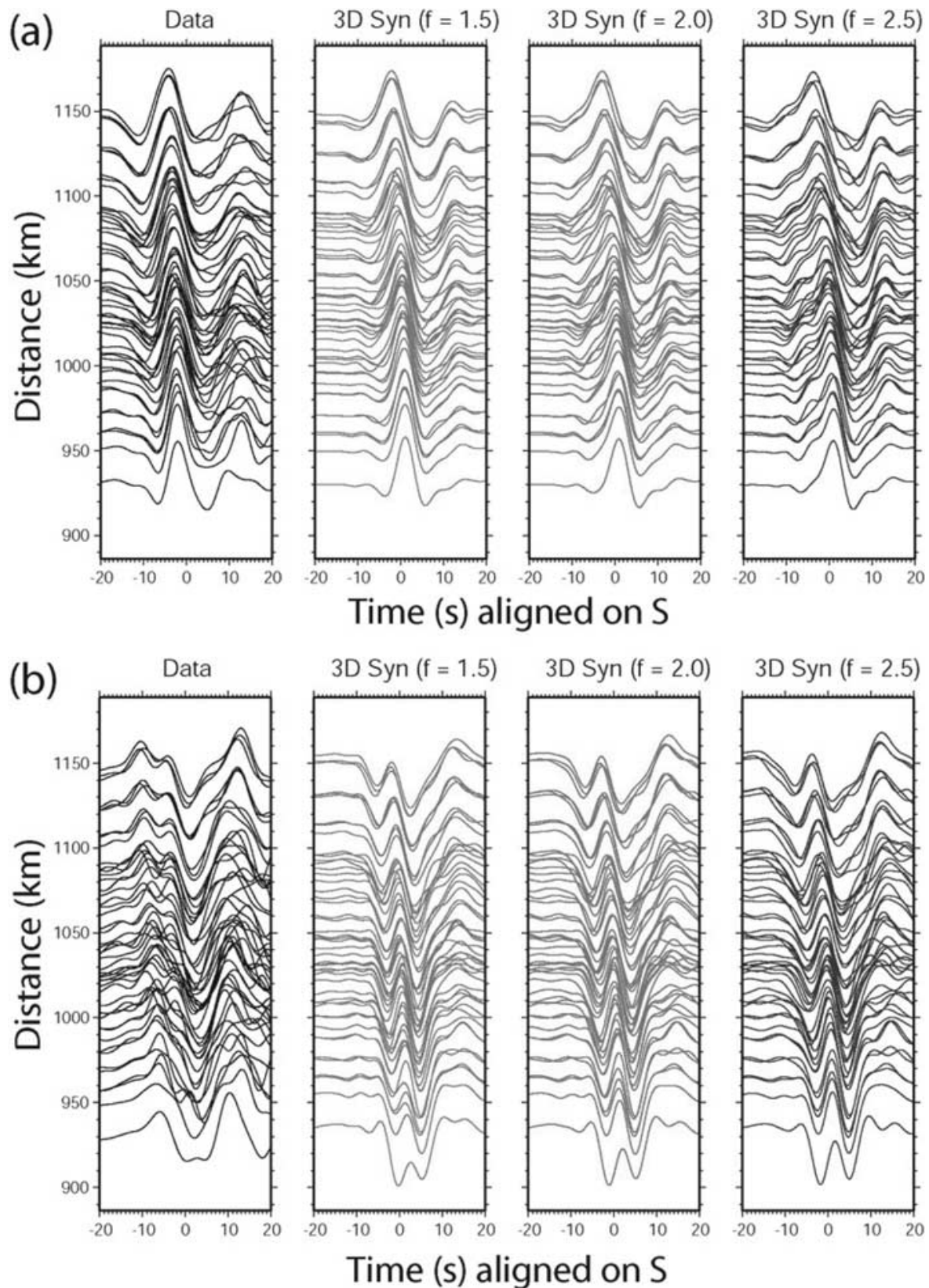

Figure 6. Waveform comparison between data and 3-D SEM synthetics in the azimuthal range 110$120^{\circ}$ for event 20020915 . The seismograms are plotted as function of distance and are aligned on the direct $\mathrm{S}$ arrivals for 1-D model IASPEI91. The SEM synthetics are calculated for three different S models with scaling factors $f=\delta \ln \beta / \delta \ln \alpha=1.5,2.0$ and 2.5. All seismograms are bandpass filtered between $6 \mathrm{~s}$ and 29 s. (a) Radial S waves. (b) Vertical S waves.

Some of this complexity is captured by the synthetics, but it is irregular due to the complicated low-velocity structure above the slab. The data and synthetics are cross correlated and time shifted for alignment. Over 500 pairs have been analyzed, with delays displayed in Figure 5a. Note that about half of the scatter for the 1-D model is reduced by the 3 -D model. About $80 \%$ of the cross-correlation coefficients fall into the range of 0.6-0.9 (Figure 5b) and the overall waveform fits between the $\mathrm{P}$ wave data and the synthetics calculated from the regional model [Zhao et al., 1994] are quite good. However, there are strong azimuthal misfit variations when the data are partitioned into the corridors shown in Figure 1a. The synthetics in corridor D have higher waveform similarity compared to the data than those in corridors A, B, 2D and C, where the slab exists. In particular in corridors $\mathrm{B}$ and $\mathrm{C}$, where the slab geometry changes rapidly with azimuth, the fits deteriorate. The smallest cross-correlation values reach 0.2 , which includes a group of synthetic waveforms with a polarity different from the data. The synthetics with cross-correlation coefficients in the range of $0.8-0.9$ have a relatively simple Gaussian pulse shape, like the data, which is the general shape of the waveforms that are not affected by the slab. Cross-correlation values in the range of $0.6-0.8$ represent waveforms with 
(a) Radial S waves
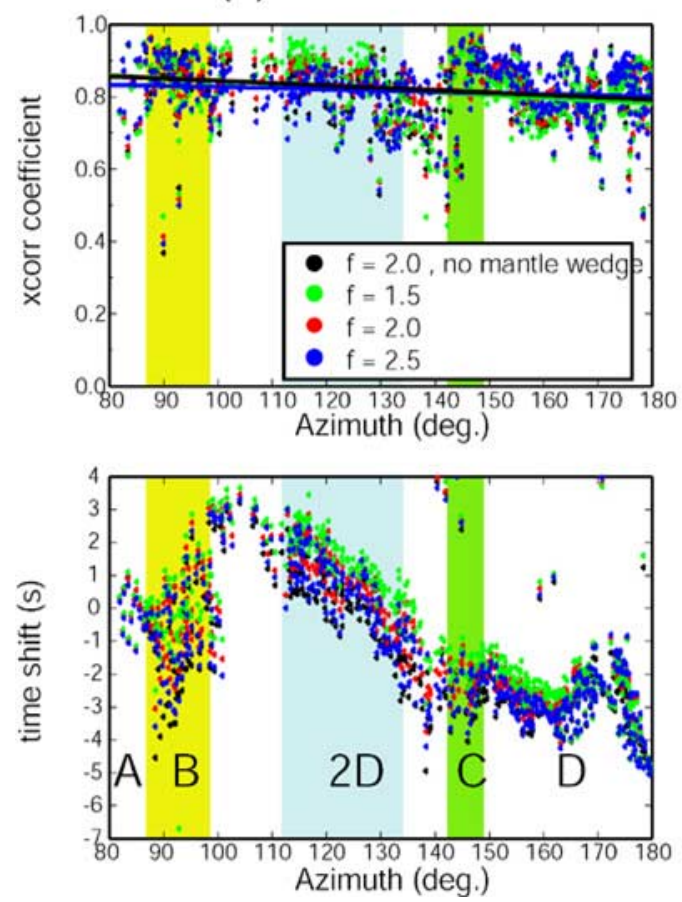

(b) Vertical S waves
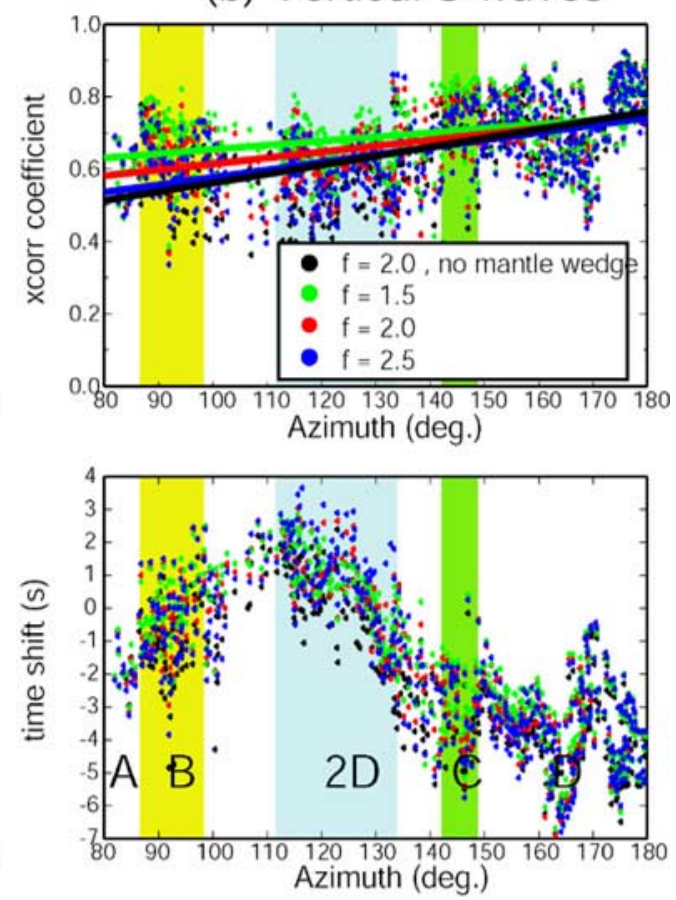

Figure 7. Cross correlation between data and SEM synthetics for $\mathrm{S}$ waves calculated for four different $\mathrm{S}$ models, with different scaling factors $f=\delta \ln \beta / \delta \ln \alpha$ to the $\mathrm{P}$ wave model. The cross-correlation results for the four different $\mathrm{S}$ models are indicated by the green dots $(f=1.5)$, red dots $(f=2.0)$, blue dots $(f=$ $2.5)$, and black dots $(f=2.0$ inside the slab only, no mantle wedge). (a) Radial S waves. (b) Vertical S waves. Note that models with $f=1.5-2.0$ produce $\mathrm{S}$ wave synthetic waveforms more similar to the data on the vertical component.

widened or dispersed pulse shapes in both synthetics and data, which is the key waveform feature in this highresolution regional model; this feature is even more obvious in SH wave data, and will be addressed in detail in the following sections. In corridor D, the synthetics are on average $2.5 \mathrm{~s}$ slower than the data. Along this corridor there is no slab and the structure is almost 1-D, indicating either that the IASPEI91 model is too slow or the baseline shift is caused by uncertainty in the source location. In corridor 2D, where the updip going wavefronts encounter the slab the most, the slab has the maximum effect on both traveltimes and waveforms. In this corridor the time shifts between data and synthetics are $1.5 \mathrm{~s}$ larger than those in corridor D.

\subsection{SV Waves}

[15] Figure 6 shows an example of a comparison between data and synthetics for SV waves on both the radial and the vertical components. These comparisons are made at periods of $6 \mathrm{~s}$ and longer, so the cross-correlation coefficients remain quite high even though the fits are not particularly good. There are similar azimuthal variations in the $\mathrm{S}$ wave cross-correlation results (Figures $7 \mathrm{a}$ and $7 \mathrm{~b}$ ). The azimuthal time shift offset is about twice as large as for $\mathrm{P}$ waves. This consistent azimuthal offset cannot be explained by increasing the velocities of the 1-D background model, since this will not change azimuthal differences but only cause uniform baseline shifts. There are two possible explanations for the offset: the slab in the regional model [Zhao et al., 1994] (above $500 \mathrm{~km}$ and in the azimuthal range from $80^{\circ}-150^{\circ}$ ) is not fast enough or, in the same azimuthal window, the regional model [Zhao et al., 1994] does not resolve the slab inside the transition zone. Since the 3-D tomographic model has high resolution in the slab above the transition zone, a slab anomaly inside the transition zone is the more reasonable explanation, and later 2-D waveform modeling will confirm this interpretation.

[16] From Figures $7 \mathrm{a}$ and $7 \mathrm{~b}$ we also note that radial SV waveforms are much less sensitive to the velocity structure than vertical SV waveforms. For all four S models we examined, the waveform similarity between data and synthetics is high and almost the same for all azimuths on the radial component, but the similarity decreases on the vertical component in the azimuthal windows where the slab exists. Least squares analysis suggests a P-to-S scaling value $f=1.5-2.0$.

\subsection{SH Waves}

[17] While the P and SV waves exhibit reasonable fits, the SH waves have low enough cross correlations to make the traveltime delay estimates unreliable except in restricted windows. A sample of SH waveforms is presented in Figure 8, where the data are plotted as a function of azimuth and aligned on the IASPEI91 traveltime. The 2-D FDM synthetics were generated from 2-D cross sections of the global and regional models (Figure 1b), as explained earlier. Note the change in polarity near $145^{\circ}$, which appears to be near a sign flip in the data, perhaps with about a $5^{\circ}$ shift to near $150^{\circ}$. Such discrepancies are common, but since we will avoid modeling data near nodes in the $\mathrm{SH}$ radiation 


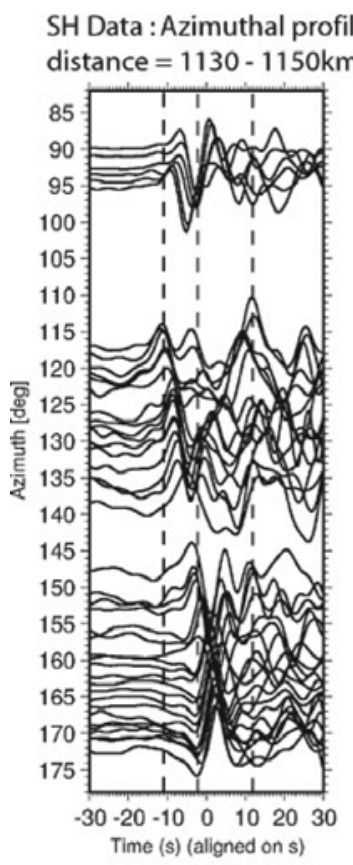

(a)

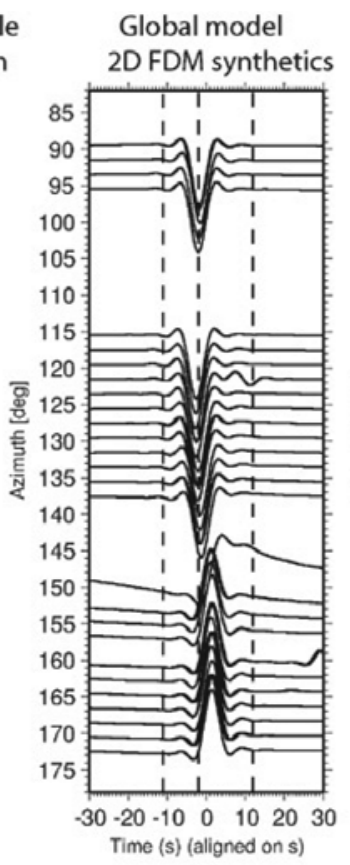

(b)

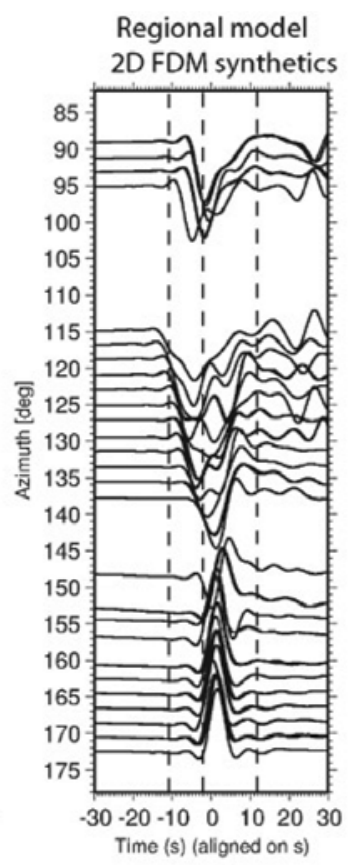

(c)

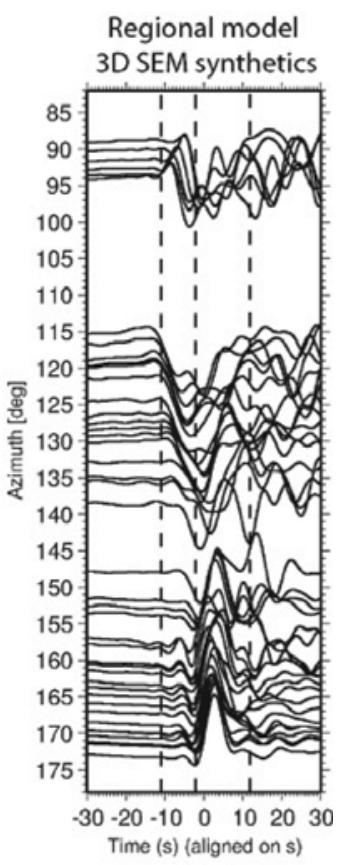

(d)

Figure 8. Azimuthal ("fan shot") profiles for the SH wave (displacement) and the corresponding synthetics. All seismograms are aligned on the direct $\mathrm{S}$ arrivals calculated based upon 1-D model IASPEI91. The $\mathrm{S}$ wave models used in the simulations are derived from the $\mathrm{P}$ wave model based upon a scaling factor $f=\delta \ln \alpha / \delta \ln \beta$. The three vertical dashed lines align with the onset of the most advanced $\mathrm{S}$ wave, the onset of the least advanced S wave, and the end of the most widened $\mathrm{S}$ wave in the data profile, respectively. (a) Azimuthal profile for SH data from event 20020915 recorded by stations at roughly the same epicentral distance $(1130-1150 \mathrm{~km})$, marked by the red circles in Figure 9. (b) The 2-D FDM synthetics calculated for Zhao's global model. (c) The 2-D FDM synthetics calculated for Zhao et al.'s [1994] regional model. (d) The 3-D SEM synthetics calculated for Zhao et al.'s regional model.

pattern we have not changed the source mechanism. However, the greater complexity in the full 3-D calculation near $150^{\circ}$ relative to $175^{\circ}$ is beginning to produce waveform distortion due to 3-D multipathing near the nodes. Working with a large array of stations helps remove source complexity issues, contrary to dealing with multiple sources and a few stations. Moreover, difficulties due to uncertainties in locations and origin times are avoided, and relative timing between stations becomes more definitive. Note that the observed traveltimes at stations near $115^{\circ}$ are nearly $10 \mathrm{~s}$ earlier than at $175^{\circ}$, and that this is largely predicted by the tomographic model $(f=2.0)$. We have modeled the $\mathrm{SH}$ waves in these azimuths with an $8 \mathrm{~s}$ source duration and assumed the same time history for other paths. For all the records within the distance range of $1130-1150 \mathrm{~km}$ the $\mathrm{SH}$ waveforms are obviously broadened in the azimuthal range from $115-150^{\circ}$, where the slab should have the strongest effect based on the cross sections displayed in Figure 1. The maximum broadening happens at around $117^{\circ}$, where the duration of the entire SH wave train is nearly $23 \mathrm{~s}$.

[18] The synthetic predictions for the regional tomographic model explain some of the observed complexity, while the global model predictions are nearly 1-D-like simple waveforms. As pointed out earlier, the data for azimuths between $115^{\circ}$ and $119^{\circ}$ are quite well behaved, in general agreement with the 2-D geometry. Moreover, the 2-D FDM synthetics and the 3-D SEM synthetics are quite similar. Thus it appears that for this corridor we can explore 2-D models and use 3-D SEM synthetics subsequently as a check. The waveform data shown in Figure 8 were recorded along an arc in distance (from $1130 \mathrm{~km}$ to $1150 \mathrm{~km}$ ), as displayed in Figure 9. A gap in coverage occurs between $115^{\circ}$ and about $95^{\circ}$, where the islands have a break. A normal record section with data plotted relative to distance is useful to study multipathing in the plane of propagation, or for detecting internal slab structure. Stations with an azimuth of $\sim 115^{\circ}$ are well suited for such an analysis.

[19] On the basis of a comparison between stacked $\mathrm{SH}$ data and FDM synthetics for an S model scaled to Zhao et al.'s [1994] $\mathrm{P}$ model with $f=2$, we can see that this model explains neither the SH traveltimes nor the SH waveforms as a function of epicentral distance (Figure 10). The first arrivals in the data are gradually advanced relative to IASPEI91 with increasing distance. The synthetic first arrival for a station at a distance of $\sim 925 \mathrm{~km}$ is $2.5 \mathrm{~s}$ slower than the data, and the differences between the synthetics and the data become less with increasing distance. In terms of waveforms, the observed secondary arrivals appear only at distances greater than $1050 \mathrm{~km}$, but in the synthetic profile, waveform widening occurs at much closer distances ( $\sim 960 \mathrm{~km})$ and the later arriving upswing phases in the data are not present in the synthetics. We interpret the first arrival as the slab phase, since it is advanced by the fast slab relative to the ambient mantle. At large distances, the propagation 


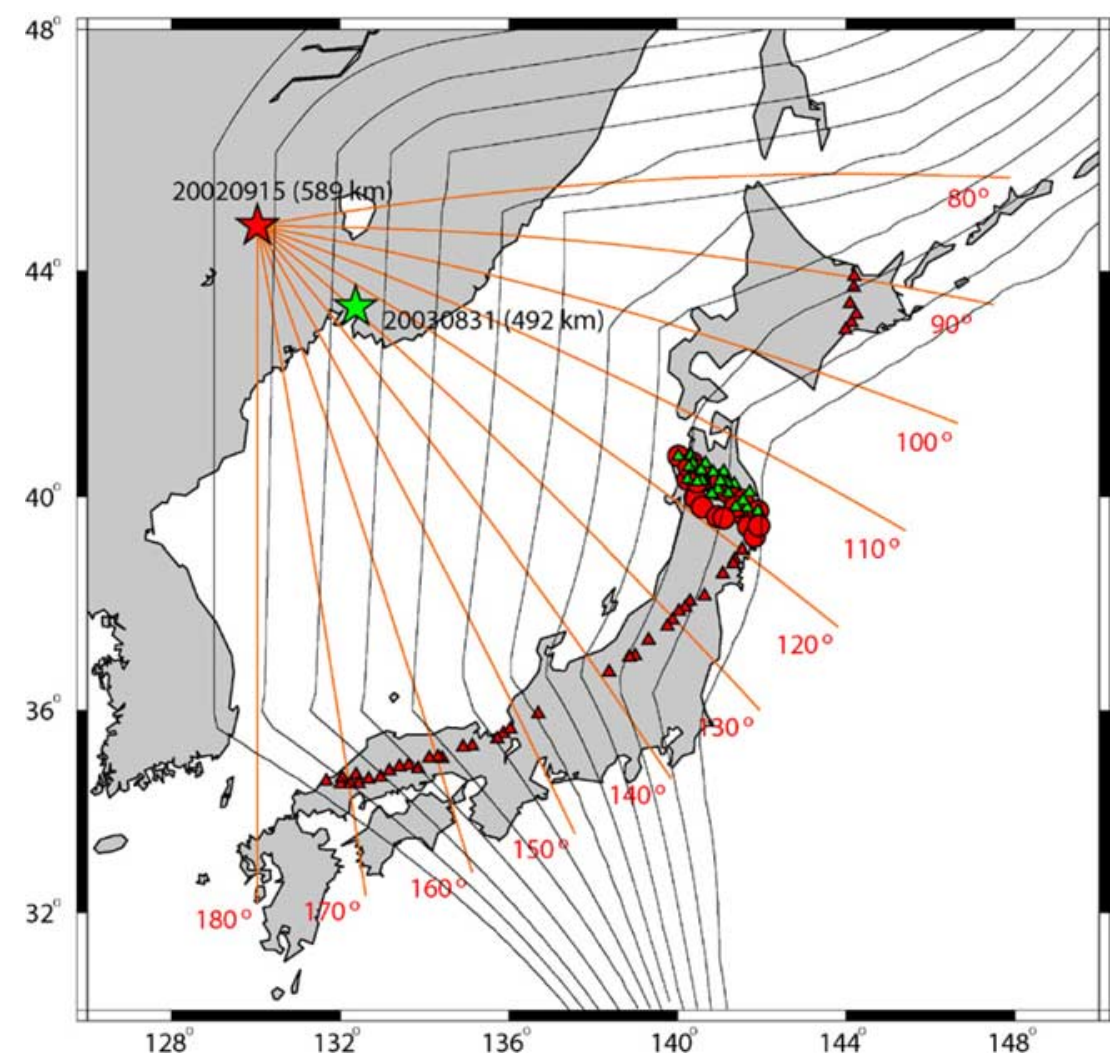

Figure 9. Map of the Japan subduction zone area. Black lines indicate slab contours used in the regional tomographic inversion by Zhao et al. [1994]. For event 20020915 (red star) the red triangles denote Hinet stations with almost the same epicentral distance $(1130-1150 \mathrm{~km})$; the red circles denote stations within the narrow azimuthal range $115-119^{\circ}$ whose corresponding raypaths sample the slab beneath corridor 2D shown in Figure 1a. The green triangles indicate the selected stations for event 20030831 (green star) whose great circle paths sample the same corridor as event 20020915. Red lines indicate representative source azimuths for event 20020915.

paths tend to be closer to the slab interface and thus are even more advanced by the fast slab. The secondary upswing phases at distances greater than $1050 \mathrm{~km}$ (Figure 10) are probably caused by slow anomalies (see section 4.1). Our 2-D waveform modeling thus proceeds by constructing a new slab model from the regional model to minimize the traveltime misfit of the slab phases, and adding low-velocity structures to produce the later arriving upswing phases using a combination of trial-and-error and grid search.

\section{Construction of the 2-D Slab Model}

[20] The regional model [Zhao et al., 1994] underpredicts the advancing of the slab phase for stations at small distances (Figure 10), and this can be explained by the lack of a slab near the earthquake source, since traveltimes at small distances are particularly sensitive to near-source velocity anomalies. In the global $\mathrm{P}$ model (Figure 1b) [Zhao, 2001], we see a stagnant slab pattern inside the transition zone. Thus it is necessary to add a slab anomaly in the transition zone of the regional model.

[21] For modeling purposes, we specify several simple polygons with uniform $S$ wave velocity anomalies: the slab above the transition zone with a dip angle of $24^{\circ}$ and the mantle wedge, whose shapes and anomalies are determined by capturing the major features of the regional model [Zhao et al., 1994]; the slab inside the transition zone, which is flattened toward the west, with its dip angle on the eastern edge and velocity anomaly undetermined. There are two endmember models produced by the following two possible scenarios: the rigid slab subducts into the transition zone with the same dip angle as on the eastern edge, or, after the slab penetrates the 410 discontinuity, the slab sinks vertically and flattens toward the west.

[22] In Zhao et al.'s [1994] regional model the thickness of the slab is predetermined to be $90 \mathrm{~km}$, and the predefined position of upper boundary is based upon previous studies of seismicity and later arrivals [Zhao and Hasegawa, 1993]. Zhao et al. [1994] included the slab in the initial model for inversion. The final tomographic slab image in the regional model thus represents a better model with constraints from both seismicity and arrival times. We want to test if increasing the slab thickness affects the waveforms. Therefore, for each of the base models we calculate 2-D synthetics with different slab thicknesses above the transition zone (thicknesses of $90 \mathrm{~km}$ and $120 \mathrm{~km}$, as shown in Figure 11).

[23] All the base models with a slab inside the transition zone $(\delta \ln \beta=5 \%)$, a slab above the transition zone $(\delta \ln$ $\beta=6 \%$ ), and a mantle wedge $(\delta \ln \beta=-4 \%)$ produce synthetics which fit the traveltimes of the first arrivals. However, the synthetic waveforms change with distance for the different base models. The synthetic waveform is 


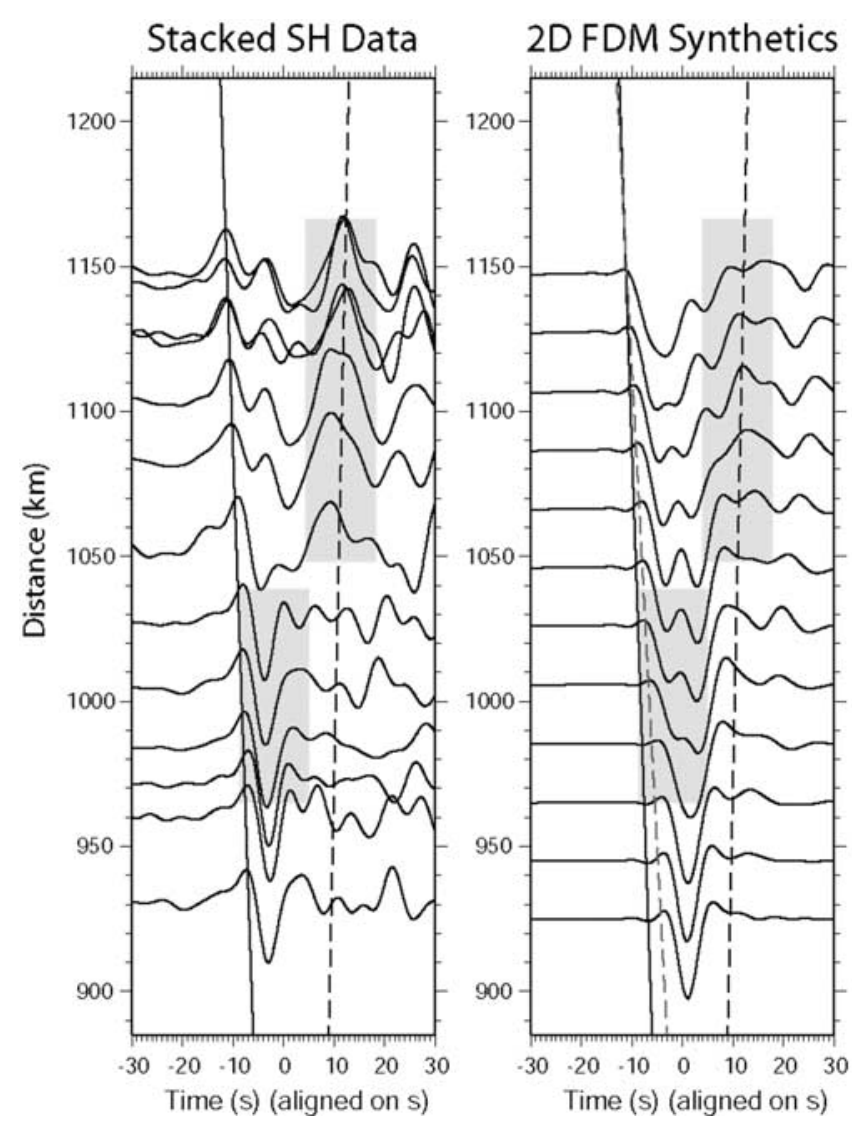

Figure 10. Comparison between stacked $\mathrm{SH}$ data and FDM synthetics. The FDM synthetics are calculated for an $\mathrm{S}$ model scaled to the regional $\mathrm{P}$ model with $f=2$. The records before stacking come from the stations marked by red circles in Figure 9. Every trace in the data record section represents a stack of records from a $2^{\circ}$ azimuthal window. The solid lines indicate the approximate first $\mathrm{S}$ arrival in the data. The gray dashed line in the right panel indicates the approximate first $\mathrm{S}$ arrivals in the FDM synthetics. The black dashed lines align with the peak of the later arriving upswing phases for stations with an epicentral distance greater than $1050 \mathrm{~km}$. Waveform differences between data and synthetics are highlighted by the gray boxes.

widened at small distances for the models shown in Figure 11a, which indicates that near-source scattering is very strong due to the close distance between the source and the eastern edge of the slab inside the transition zone, and this scattering is even stronger when the slab is thinner. The base models shown in Figure 11b produce synthetic waveforms more similar to the data for stations at smaller distances. However, the thinner slab (thickness of $90 \mathrm{~km}$ ) produces widened slab phase waveforms for stations at larger distances, which are not observed in the data. The base models with a slab thickness greater than $120 \mathrm{~km}$ produce similar waveforms to the one with a thickness of $120 \mathrm{~km}$. The upgoing wavefronts with this specific source station geometry are only sensitive to the upper slab interface and partially sensitive to the bottom interface if the slab is thin. When the slab thickness is greater than $120 \mathrm{~km}$, the bottom interface does not significantly affect the slab phase waveform. Thus the base model is fixed with a slab thickness of $120 \mathrm{~km}$, and the eastern edge of the slab inside the transition zone is located far enough away from the source so as not to produce significant near-source scattering. We specify the dip angle inside the transition zone to be $33^{\circ}$, which appears sufficient for the purpose of this waveform modeling study.

\subsection{Slab Models With a Low-Velocity Layer}

[24] Although the modified base model significantly reduces the traveltime misfits, it does not produce the secondary arrivals present in the data, especially at distances larger than $1050 \mathrm{~km}$. A reversal of polarity of the later arriving phases would indicate the existence of a lowvelocity waveguide along the propagation path, with high velocities on either side. There are inferences of such a lowvelocity layer with a thickness of $5-10 \mathrm{~km}$ and relative $\mathrm{P}$ wave velocity perturbations $\delta \ln \alpha$ of $-6 \%$ on top of the slab beneath northeastern Japan from differential traveltime between direct P and P-to-S converted phase [Matsuzawa et al., 1986]. Observations of seismic signals with lowfrequency onset followed by high-frequency coda have been modeled by Furumura and Kennett [2005]. Motivated by this study, we add a low-velocity layer (LVL) on top of the slab (Figure 12b) and describe the LVL with the following three parameters: its thickness (DL), its depth extent (HL), and its relative shear wave velocity perturbation $(\delta \ln \beta)$. In general, as discussed by Martin et al. [2003], the velocity contrast between the LVL and its surroundings influences the waveform most. However, as discussed in section 3 , the velocity perturbation inside the slab is well constrained in the base model by differential traveltimes with increasing distances, and thus $\delta \ln \beta$ inside the LVL is a controlling parameter.

[25] We tested nine types of models with different LVL geometries $(\mathrm{DL}=10 \mathrm{~km}, 20 \mathrm{~km}$, and $30 \mathrm{~km}$, and $\mathrm{HL}=$ $200 \mathrm{~km}, 300 \mathrm{~km}$, and $400 \mathrm{~km}$ ) (Figures 12c, 12d, and 12e). We fix DL and HL for each of the nine combinations and perform a grid search for the best $\delta \ln \beta$ which produces significant later arriving upswings with the right timing for stations at the maximum distance of $1150 \mathrm{~km}$. The differential time between the onset of the SH wave and the peak of the later arriving upswing is about $23 \mathrm{~s}$ at $1150 \mathrm{~km}$. The waveform change is quite sensitive to the depth (i.e., length) of the LVL, and only models with depths approaching $300 \mathrm{~km}$ reproduce the characteristics of the observed waveforms at all distances.

[26] When the LVL extends deeper $(\mathrm{HL}=400 \mathrm{~km})$, the energy gets trapped in the LVL too early and causes too much pulse widening in the synthetics at close distances compared to the data. When the LVL is too shallow (HL = $200 \mathrm{~km}$ ), there is insufficient energy trapping for the later arriving upswings. Even if we make the LVL extremely slow with $\delta \ln \beta=-56 \%,-42 \%$ and $-28 \%$, corresponding to $\mathrm{DL}=10 \mathrm{~km}, 20 \mathrm{~km}$, and $30 \mathrm{~km}$, respectively, the synthetic waveforms at distances of $\sim 960 \mathrm{~km}$ and traveltimes at distances larger than $1050 \mathrm{~km}$ disagree with the data. For the best fitting models with a LVL length of $\sim 300 \mathrm{~km}$ there are still significant trade-offs between thickness DL and shear velocity perturbation $\delta \ln \beta$, such that a smaller DL combined with a more negative $\delta \ln \beta$ can produce the same waveform features at all distances. The 
(a)
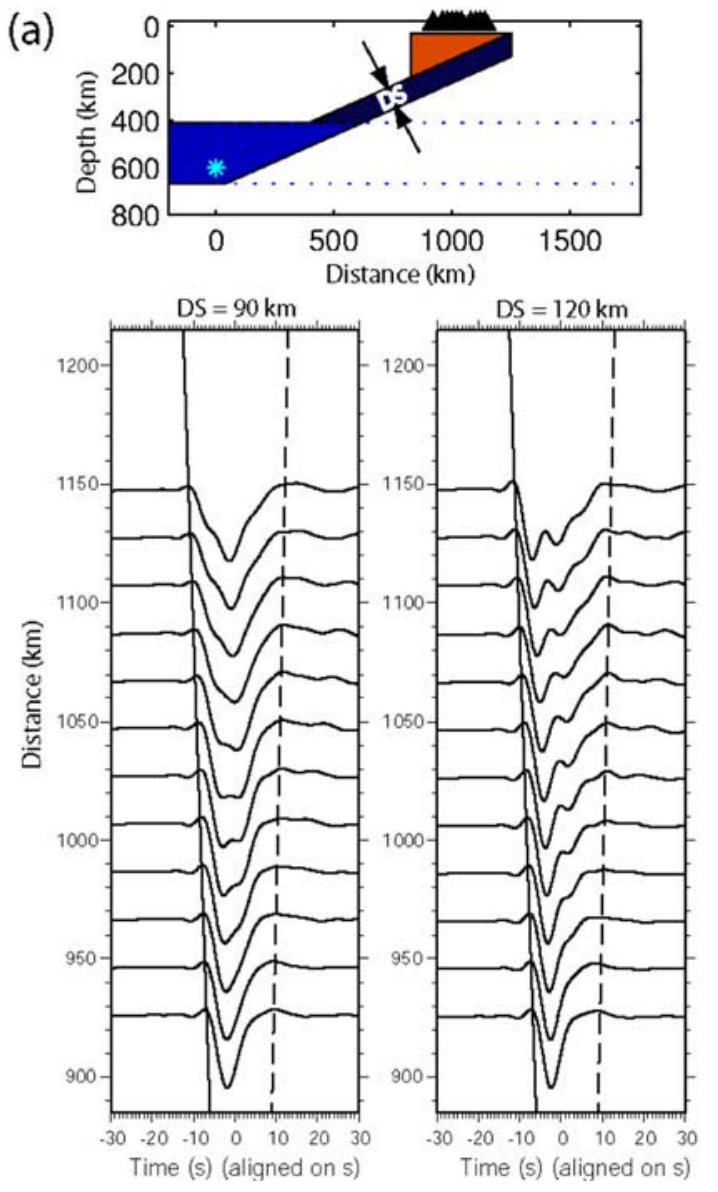

(b)
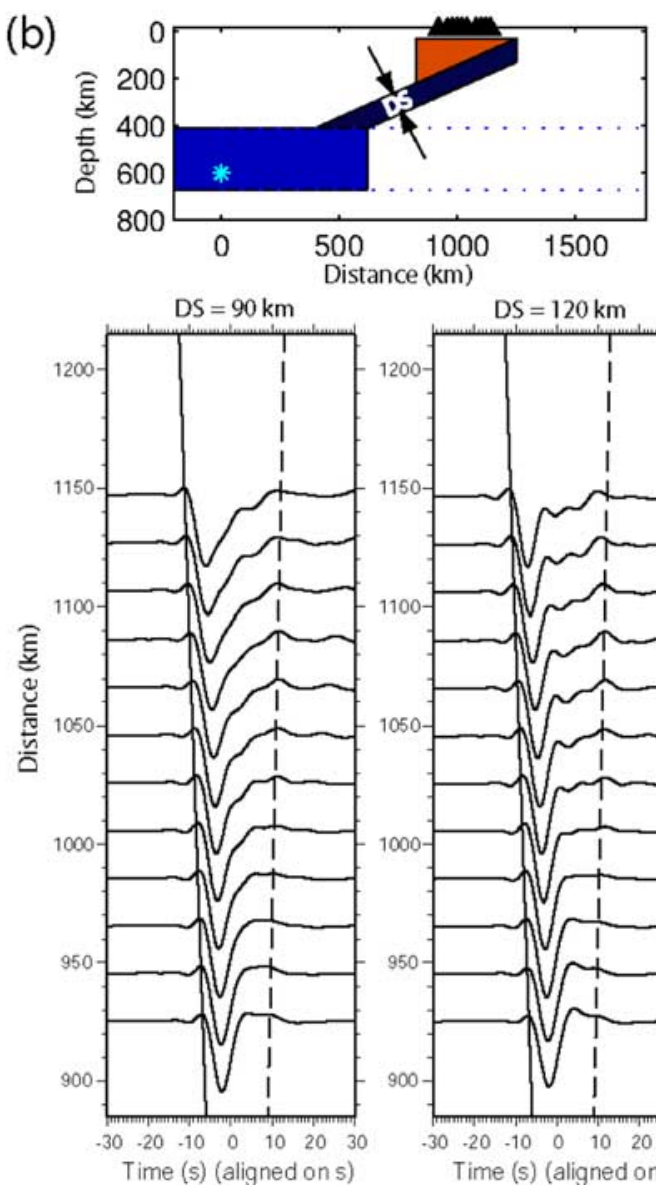

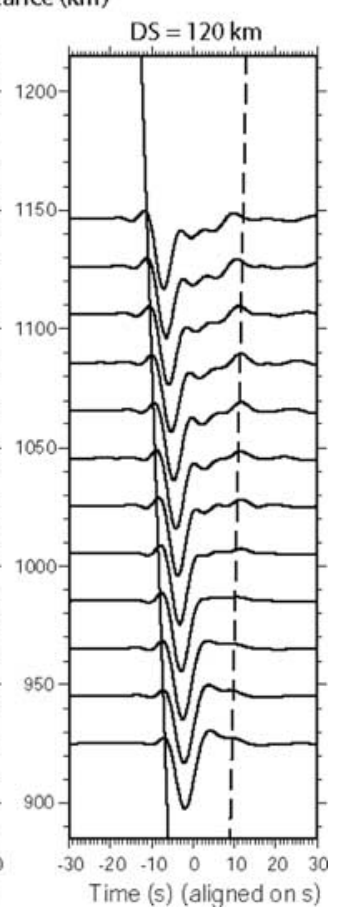

Figure 11. FDM waveforms for base models with a slab inside the transition zone. Mantle wedge (orange polygon), $\delta \ln \beta=-4 \%$. Slab above the $410 \mathrm{~km}$ discontinuity (dark blue polygon), $\delta \ln \beta=6 \%$. Thickness of the slab (DS), $90 \mathrm{~km}$ or $120 \mathrm{~km}$. Slab inside the transition zone (blue polygon): $\delta \ln \beta=5 \%$. The dark solid and dashed lines are the same as those in Figure 10. (a) Eastern edge of the slab in the transition zone has the same dip angle as the slab above. (b) Eastern edge of the slab in the transition zone is vertical. The first two panels on the bottom denote FDM record sections for the model shown in Figure 11a with slab thicknesses of $90 \mathrm{~km}$ and $120 \mathrm{~km}$, respectively. Figure $11 \mathrm{~b}$ (bottom) denotes FDM record sections for the model shown in Figure $11 \mathrm{~b}$ (top) with slab thicknesses of $90 \mathrm{~km}$ and $120 \mathrm{~km}$, respectively.

2-D synthetics for this deep event thus cannot distinguish between a model with $\mathrm{HL}=300 \mathrm{~km}, \mathrm{DL}=10 \mathrm{~km}$, and $\delta \ln$ $\beta=-28 \%$, a model with $\mathrm{HL}=300 \mathrm{~km}, \mathrm{DL}=20 \mathrm{~km}$, and $\delta \ln \beta=-14 \%$, and a model with $\mathrm{HL}=300 \mathrm{~km}, \mathrm{DL}=$ $30 \mathrm{~km}$, and $\delta \ln \beta=-8 \%$. Note that attenuation is currently not considered in the numerical simulations, and this may cause overestimation of either the layer thickness or the shear wave velocity reduction. Thus our investigation only provides upper limits for these two parameters. For the sake of simplicity, we will take the model with a $20 \mathrm{~km}$ thick LVL as a starting point for further refined waveform modeling.

\subsection{Mantle Wedge Models}

[27] Next, we investigate the heterogeneity in the mantle wedge by testing the three simple models shown in Figure 13. The slow part of the mantle wedge has an $8 \%$ shear wave velocity reduction; models with an even slower mantle wedge alter the trend of traveltime with increasing distance. Overall, the heterogeneity in the mantle wedge does not change the waveforms very much. Adding the wedge-shaped low-velocity part (model 2) helps the development of later arrivals, indicated by arrows in Figure 13d. Resolving detailed structure inside mantle wedge would require data from closer and shallower events, as in the study by Furumura and Kennett [2005]. Our final 2-D model has the following characteristics (model 2): in the upper mantle, the dip angle of the slab is $\sim 24^{\circ}$, and the slab has a uniform relative compressional wave velocity anomaly $\delta \ln \alpha$ of $4.5 \%$ and a uniform relative shear wave anomaly $\delta \ln \beta$ of $6.0 \%$; inside the transition zone, the eastern edge of the slab has a dip angle of $33^{\circ}$ or larger and the slab flattens toward the west, and inside the slab in the transition zone $\delta \ln \alpha=3 \%$ and $\delta \ln \beta=5 \%$. The low-velocity layer (LVL) on top of the slab is extremely slow with $\delta \ln \alpha=-7 \%$ and $\delta \ln \beta=-14 \%$, assuming the LVL is $20 \mathrm{~km}$ thick and extends down to $300 \mathrm{~km}$; there is a slow region of the mantle wedge adjacent to the LVL with $\delta \ln \alpha=-4 \%$ and $\delta \ln \beta=-8 \%$. We convolve the raw synthetics with empirical source time 

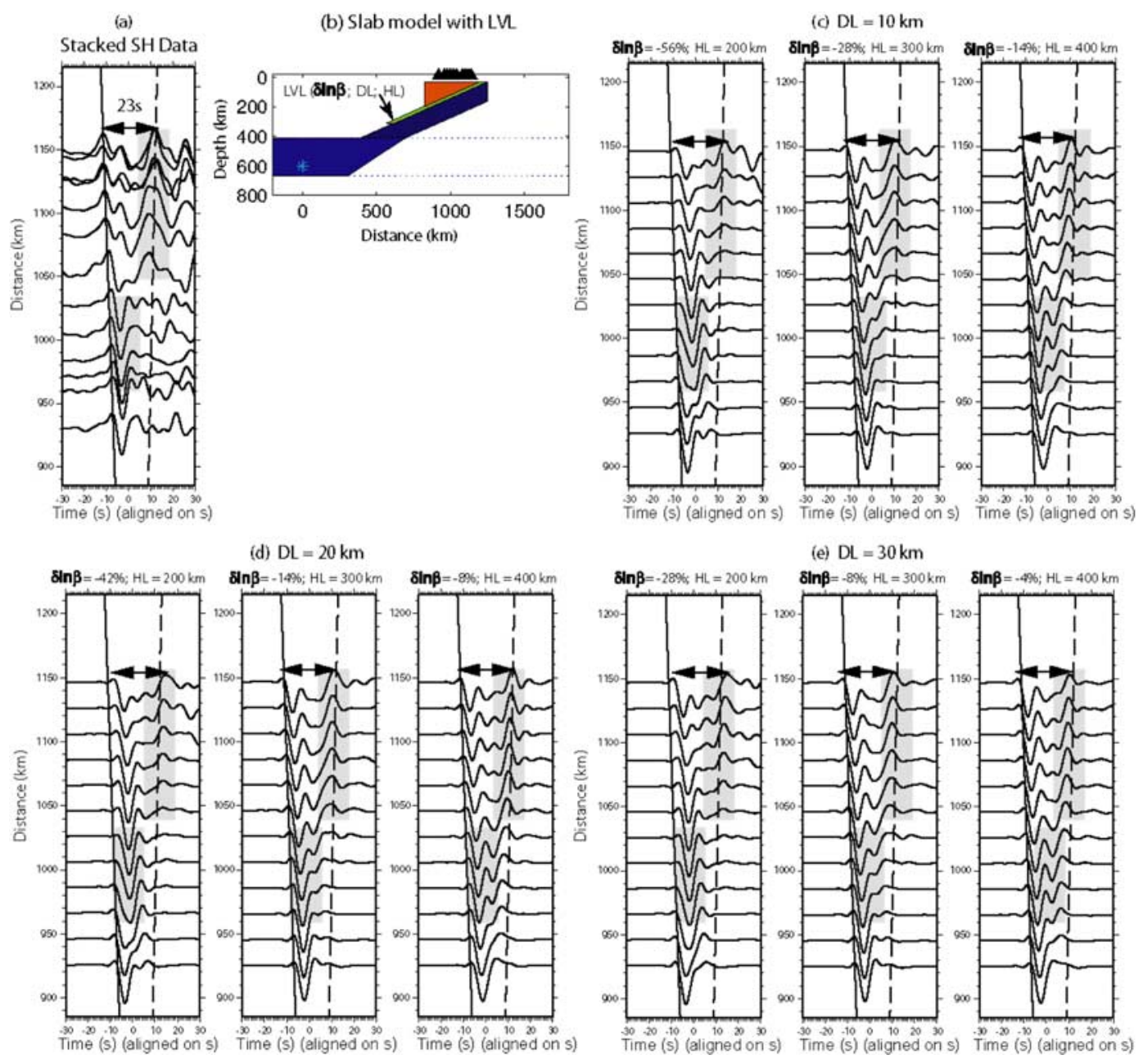

Figure 12. FDM simulations for slab models with a low-velocity layer (LVL). (a) Stacked SH data. (b) LVL indicated by the green polygon. It is characterized by its thickness (DL), its maximum depth (HL), and its relative shear wave velocity perturbation $(\delta \ln \beta)$. The black triangles indicate station locations. (c, d, e) Synthetic waveforms calculated for nine models with different thicknesses DL (10, 20, or $30 \mathrm{~km})$, and lengths HL $(200,300$, or $400 \mathrm{~km})$. The length of the bar with two-way arrowheads indicates the largest separation between the first arrival and the later arriving upswing phase, which is $23 \mathrm{~s}$ at a distance of $1150 \mathrm{~km}$. The dashed lines, solid lines, and gray boxes are the same as those in Figure 10. The comparison between data and synthetics indicates models with a LVL extending over a length of $300 \mathrm{~km}$ are preferable.

functions for both $\mathrm{P}$ and $\mathrm{SH}$ waves as discussed earlier. FDM synthetics are shown in (Figure 14) and these agree well with the observations at distances most affected by the slab.

\section{SEM Verification}

[28] In this section we use SEM to validate model 2 (Figure 13b), which is derived from tangential S waveforms for one event (20020915). We calculate SEM synthetics for all three components for the same event, as well as a complementary shallower event (20030831). We implement model 2 in the 3-D SEM mesh by sweeping it cylindrically around a vertical axis through the epicenter, since it is reasonable to assume that the structure of the region beneath the examined stations is two-dimensional based on discussions in the previous sections.
[29] Figure 15 shows three-component comparisons between data and 3-D SEM synthetics for both events. Event 20030831 is almost $100 \mathrm{~km}$ shallower than event 20020915 , recorded by stations within the same corridor (Figure 9), so the raypaths sample similar regions of the slab. The comparison between data and synthetics in Figure 15 indicates the quality of the fit on all three components. In general, the synthetics calculated for model 2 capture the correct differential traveltime for the first arrivals at different distances, the dispersion characteristics of the $\mathrm{SH}$ waveforms at large distances, and the relative amplitude ratio between the first and later arrivals for vertical $\mathrm{S}$ waves. For the same source time function, SEM simulations at twice the resolution lead to the same conclusions for $\mathrm{S}$ waves, thereby demonstrating that the resolution of the SEM mesh shown in Figure 3 is sufficient to capture model 2 . For $\mathrm{P}$ waves only the highresolution results can capture the distortion around $3 \mathrm{~s}$, 
(a)

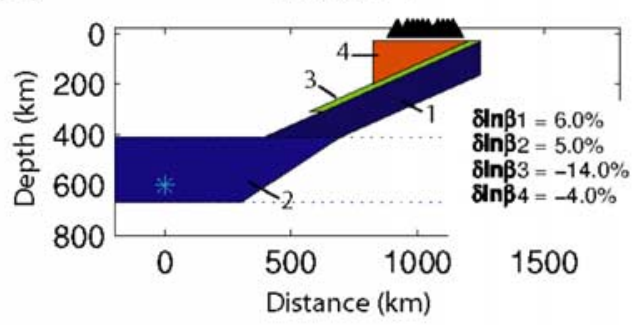

(b)

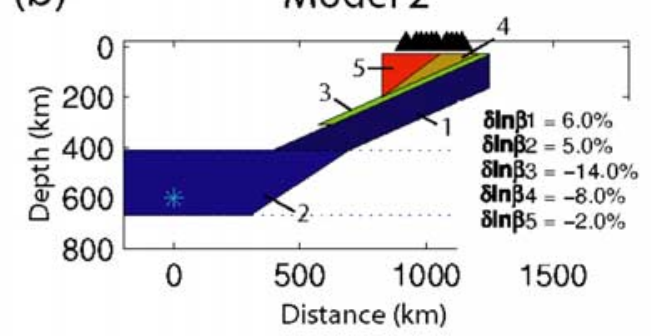

(c)

Model 3
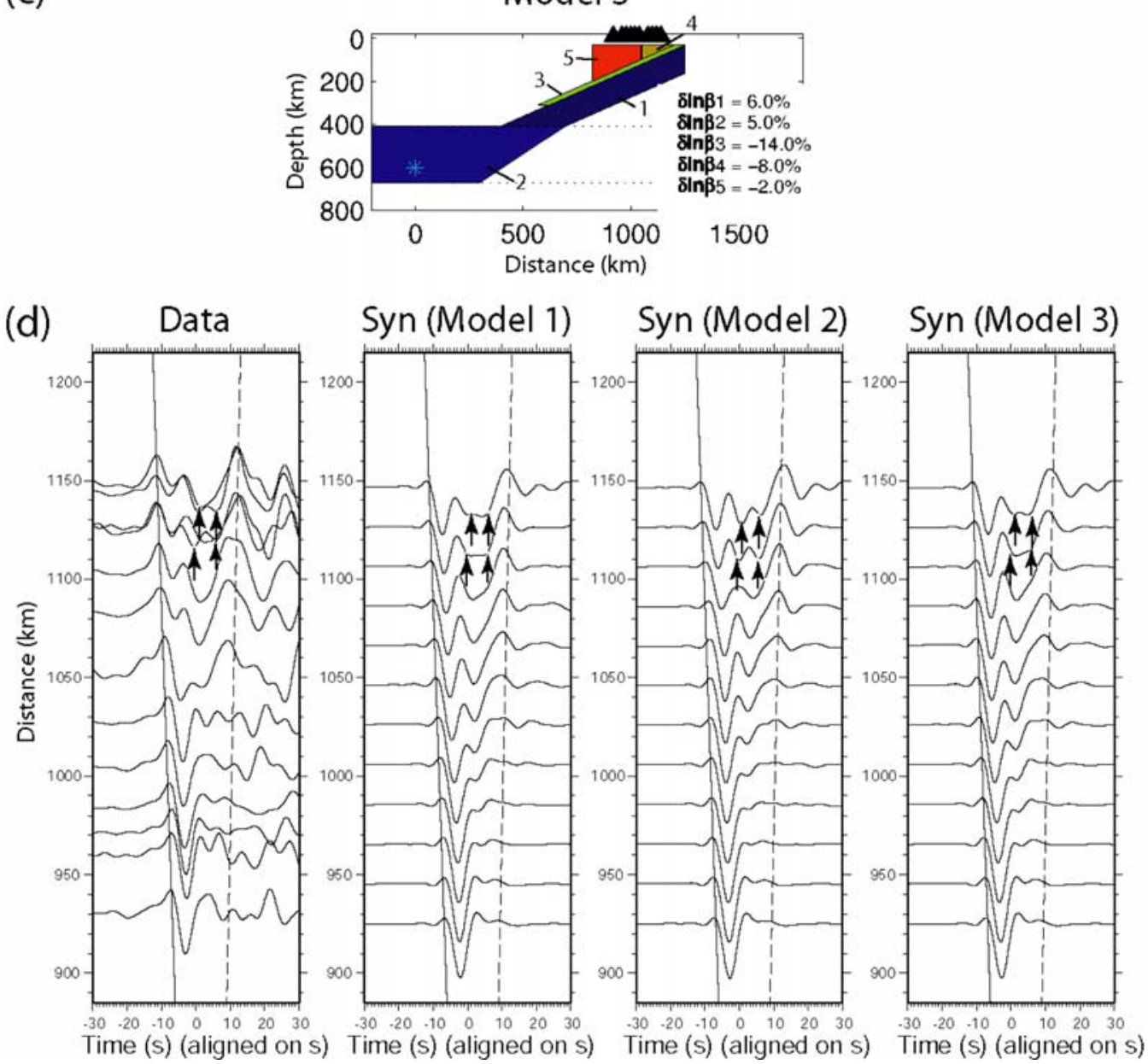

Figure 13. FDM simulations for three models with different types of mantle wedges. (a) Model 1, uniform mantle wedge. (b) Model 2, mantle wedge with a slow region (yellow) starting at $200 \mathrm{~km}$. (c) Model 3, mantle wedge with a slow part (yellow) starting at $100 \mathrm{~km}$. In Figures 13a, 13b, and 13c the shear wave velocity perturbation inside each region of the model is indicated by values of $\delta \ln \beta$ shown in the lower right corner of the model. (d) Data and synthetic waveform comparison. The arrows indicate multiple later arrivals at large distances. The left column shows the SH data, and the subsequent columns show SH FDM synthetics for models 1 (Figure 13a), 2 (Figure 13b), and 3 (Figure 13c), respectively.

which is illustrated in Figure 15; there is a $2.5 \mathrm{~s}$ baseline time shift applied to all traces. Notice the arrival times for vertical $\mathrm{P}$ waves are well captured by model 2 .

\section{Discussion}

[30] From our 2-D FDM waveform modeling we conclude that the later arriving upswing SH phases can be produced by a low-velocity layer on top of the slab. The waves propagating along the dip of the slab trap a significant amount of energy inside the low-velocity layer, which manifests itself as large-amplitude upswings in the seismogram. These upswings are also observed at other stations located in the azimuthal range from $110^{\circ}$ to $140^{\circ}$; thus the LVL can be a general feature on top of the slab beneath northeastern region of Honshu island.

[31] In order to better understand energy trapping in the slow waveguide, we examine two additional models based 

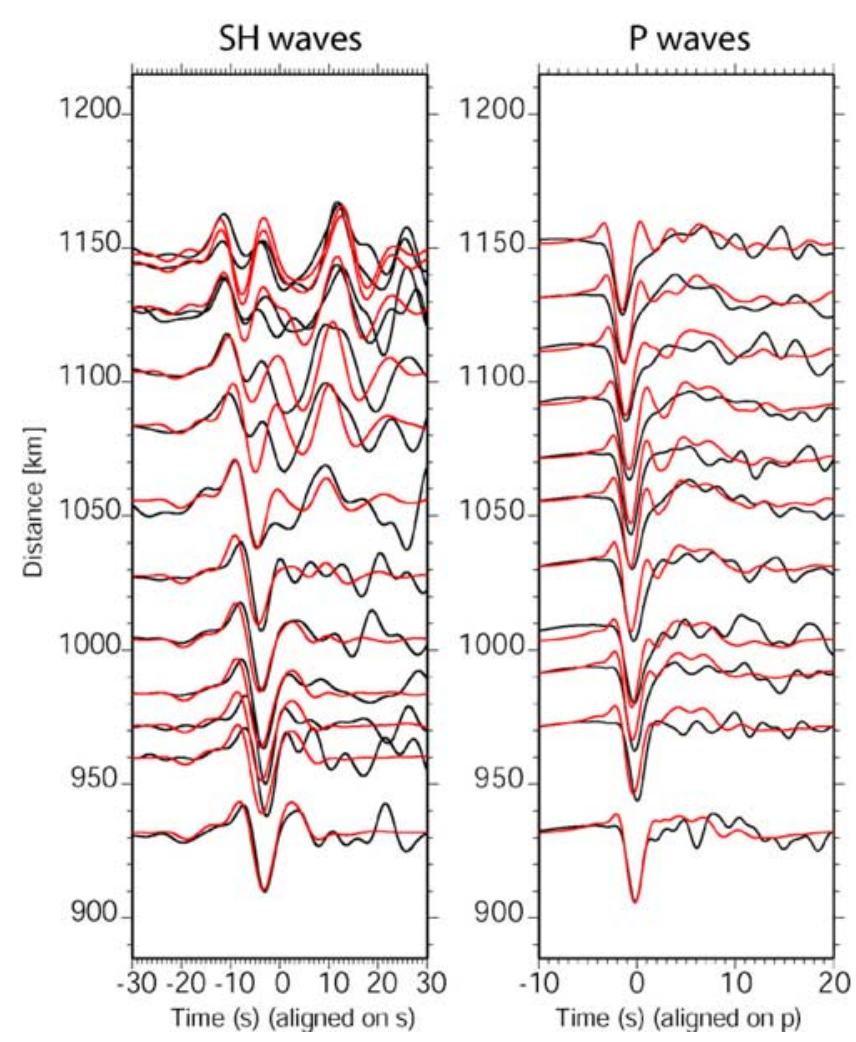

Figure 14. Waveform fits between the data (black lines) and FDM synthetics (red lines) for event 20020915. SH waves are band-pass filtered between $6 \mathrm{~s}$ and $29 \mathrm{~s}$, and P waves are band-pass filtered between $1 \mathrm{~s}$ and $29 \mathrm{~s}$. The synthetics are obtained by convolving the numerical Green's function with the empirical source time function.

upon 3-D SEM simulations: one model has a slab with a LVL but no mantle wedge; the other has only the slab and no low-velocity anomalies (Figure 16). The simulation results for the first model show that on the tangential component of the stations beyond an epicentral distance of $1050 \mathrm{~km}$ the later arriving upswings still appear, but their amplitude is not as large as for model 2 . This indicates that a slow mantle wedge helps energy to accumulate in the later arrivals, which is consistent with what is observed on the vertical component. The first-arriving pulses on the vertical component have relatively large amplitudes compared to those calculated for model 2. For the second model with only the slab, the first arrivals advanced by the slab are predominant on the tangential component, but there are almost no secondary $\mathrm{S}$ arrivals. Radial $\mathrm{S}$ waves show much larger amplitude ratios of the first arrival relative to the secondary arrival. Thus the 3-D SEM simulations further verify that an elongated slow waveguide helps to trap energy in the secondary $\mathrm{S}$ arrivals. On the radial component, $\mathrm{S}$ wave dispersion for either model is not obvious, but the $\mathrm{S}$ waveform at a distance of $1150 \mathrm{~km}$ is clearly widened compared to those at closer distances. The cross-correlation results (Figure 17) further verify that model 2 fits the SH waveforms and arrival times better than the regional starting model. For vertical $\mathrm{S}$ waves the improvement is not as obvious as for $\mathrm{SH}$ waves, but the overall waveform fits improve from an average cross correlation of 0.6 to 0.7 , and traveltime misfits for distant stations are reduced from $2 \mathrm{~s}$ to $0.5 \mathrm{~s}$. The waveform fits for model 2 with or without a mantle wedge are not substantially different, but waveforms in model 2 with just the slab and no LVL are distinctly different. Thus the LVL is an important element in the final model, and the waveform fits are very sensitive to this structure, but not to the mantle wedge.

[32] These waveguide phenomena are clearly illustrated in the 2-D FDM snapshots of SH wave propagation shown in Figure 18. Note that the presence of the fast slab advances the wavefront, whereas the LVL and the slow mantle wedge both delay and amplify the wavefield. The wavefront is advanced by the fast slab, and at the same time, in the confined LVL waveguide with a thickness comparable to the wavelength of the $\mathrm{S}$ waves, a slow wavefront with significant energy is formed from the original wavefield behind the fast wavefront (Figure 18a). Inside the slow mantle wedge the two wavefronts start to split again (Figure 18b), and these wavefronts reach the surface at different times. The undistorted part of the wavefront unaffected by the slab sweeps the surface, is recorded by stations closer to the epicenter, and displays only one SH pulse with a large amplitude in the seismogram (Figure 18c). For stations at intermediate distances, one slow and one fast wavefront are recorded, exhibiting the distinct two-pulse waveforms (Figure 18d). For stations further away, the seismograms record three or more wavefronts arriving sequentially, which results in more dispersed $\mathrm{S}$ waveforms with smaller amplitudes (Figure 18e). Note that the amplitude of these low-frequency waveforms decreases toward the eastern seaboard of Japan. This is different from the large abnormal intensity observed by Furumura and Kennett [2005], which is dominated by high-frequency $(>1 \mathrm{~Hz})$ signals. The decoupling mechanism surely has some influence on the waveforms, and the degree of influence depends not only on the slab geometry, but also on the source and receiver locations. As the trapped waves approach the volcanic front, the slow mantle wedge gradually separates the slow wavefronts from the direct $\mathrm{SH}$ wavefronts. The bending slab decoupling mechanism of guided waves discussed by Martin et al. [2003] does not explain our observations, as the previously imaged slab in the 2-D cross section has relatively constant dip even above $200 \mathrm{~km}$, thus there is no obvious bending. The guided wave decoupling is more likely being enhanced by the low-velocity mantle wedge, similar to a mechanism proposed by Fukao et al. [1983] and Hori [1990], the leaking of trapped energy. Moreover, even without the low-velocity mantle wedge, a certain amount of trapped energy still can be transmitted to the stations near the LVL, as shown in Figure 16a, which could be due to the long travel paths, the near source velocity structure and the relative position of the source with respect to the LVL.

[33] As discussed previously, there are trade-offs between the width of the waveguide and the shear wave velocity reduction inside the waveguide. The LVL must have a certain minimum width compared to the dominant wavelength of the shear waves. The characteristic period of the Hi-net data is about $6 \mathrm{~s}$, and the average shear wave velocity of the 1-D reference model in the upper mantle is $5 \mathrm{~km} / \mathrm{s}$. Thus the characteristic wavelength of the shear waves propagating inside the LVL is $\sim 30(1+\delta \ln \beta) \mathrm{km}$. We 

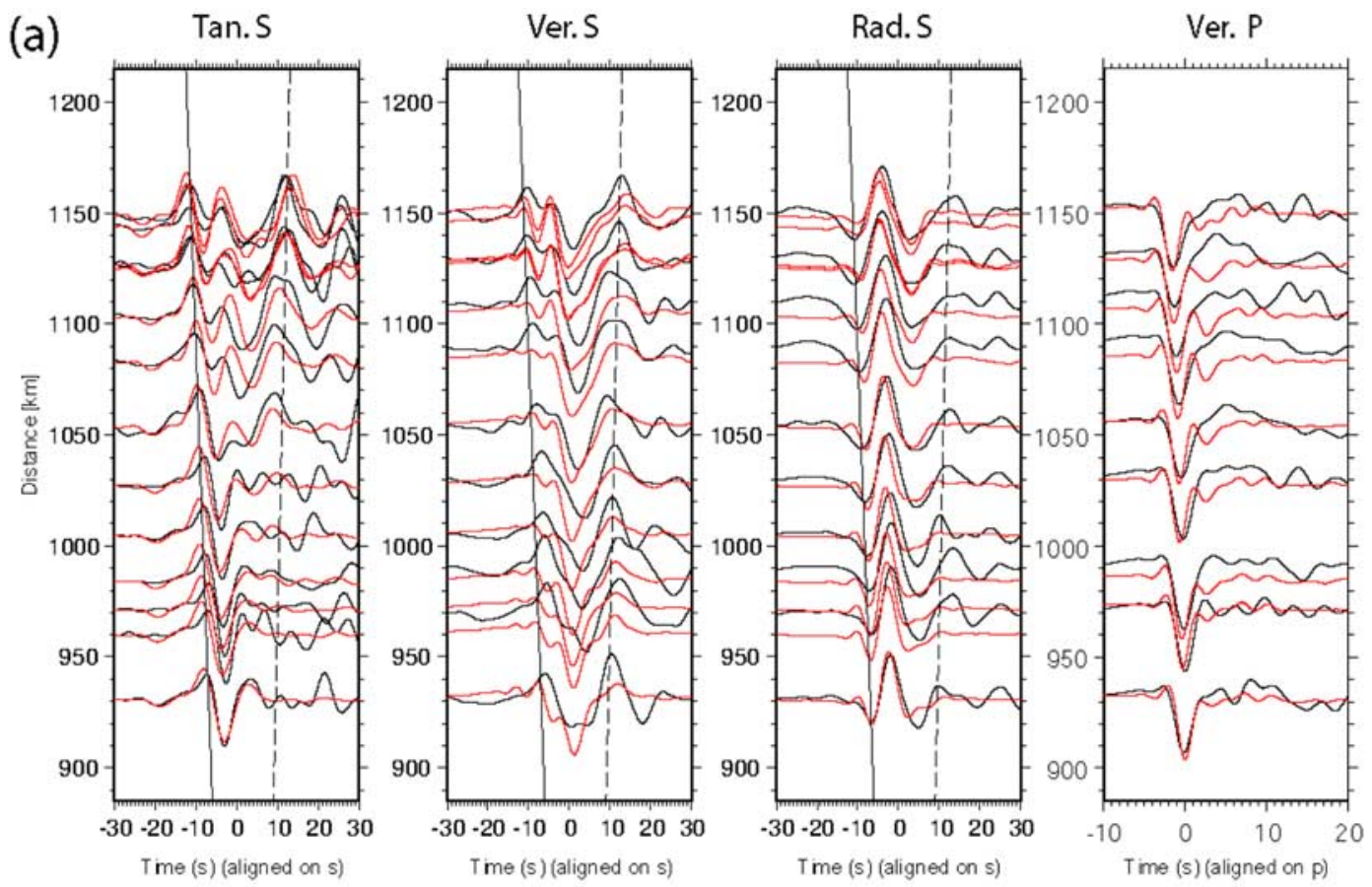

(b)

Tan. S

Ver. S

Rad.S
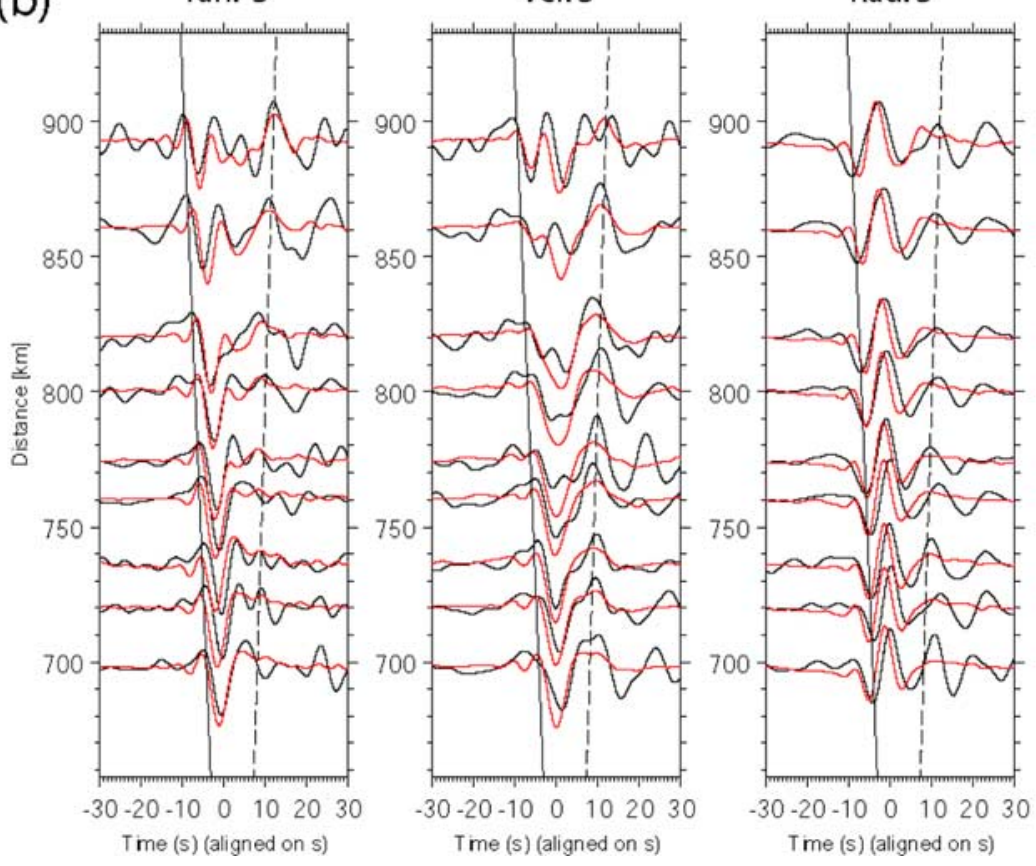

Ver. $\mathrm{P}$

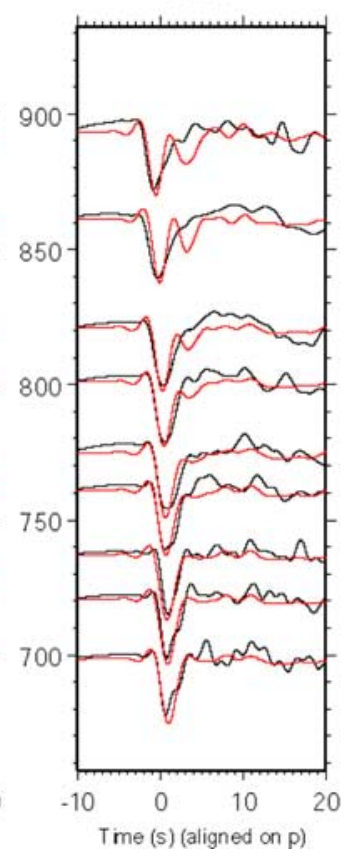

Figure 15. Three-component $S$ waveform and vertical $P$ waveform comparisons between data (black lines) and 3-D SEM synthetics (red lines). SEM synthetics are calculated for model 2 in Figure 13b. Both data and synthetics for $\mathrm{S}$ waves are filtered between $6 \mathrm{~s}$ and $29 \mathrm{~s}$, and for P waves between $3 \mathrm{~s}$ and $29 \mathrm{~s}$. (a) Event 20020915 (depth $589 \mathrm{~km}$ ). (b) Event 20030831 (depth $492 \mathrm{~km}$ ). Model 2 is our preferred model and fits the data for both events on all three components adequately.

experimented with different values of the width of the LVL for fixed values of $\delta \ln \beta$, and found that if the thickness of the LVL is less than half of this wavelength the waveguide becomes too narrow to trap sufficient energy. For example, with $\delta \ln \beta=-14 \%$ the wavelength is approximately $26 \mathrm{~km}$ and only when its width is larger than $13 \mathrm{~km}$ does the waveguide trap sufficient energy.
[34] On the basis of the SH waveform modeling (Figure 12), the LVL exists in a depth range starting from the Moho to at least $\sim 300 \mathrm{~km}$. The scaling factor $f$ is found to be 1.5-2.0 based upon 3-D SEM simulations (illustrated in Figures 6 and 7), and therefore $\delta \ln \alpha$ is $-16 \pm 3 \%,-8 \pm$ $2 \%$ and $-5 \pm 1 \%$ for a $10 \mathrm{~km}, 20 \mathrm{~km}$, and $30 \mathrm{~km}$ thick LVL, respectively. Although there is a trade-off between the 
(a)

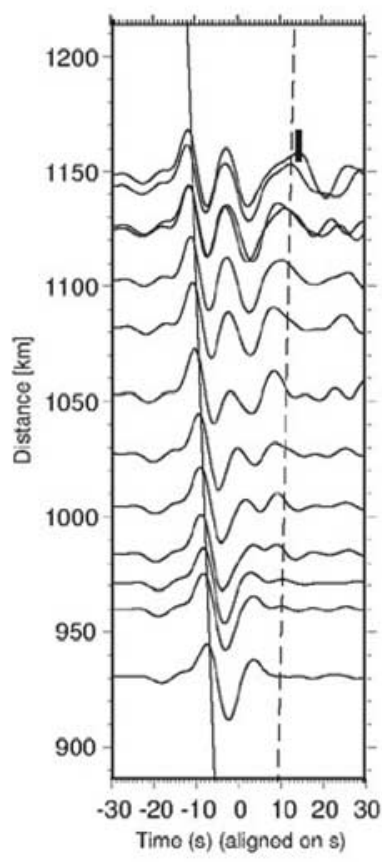

(b)

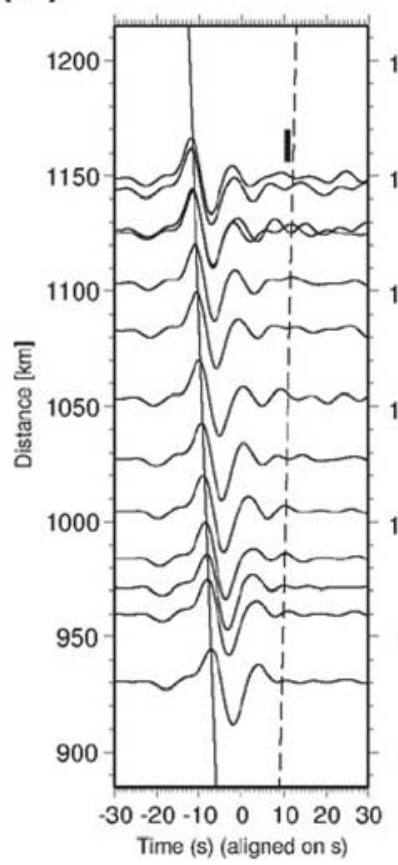

Tan.

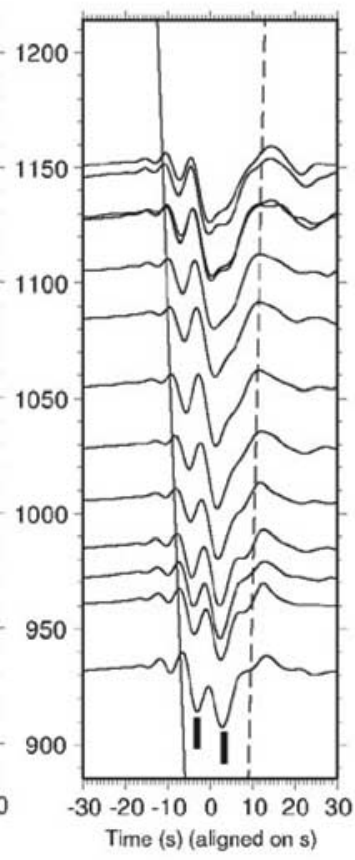

Ver.

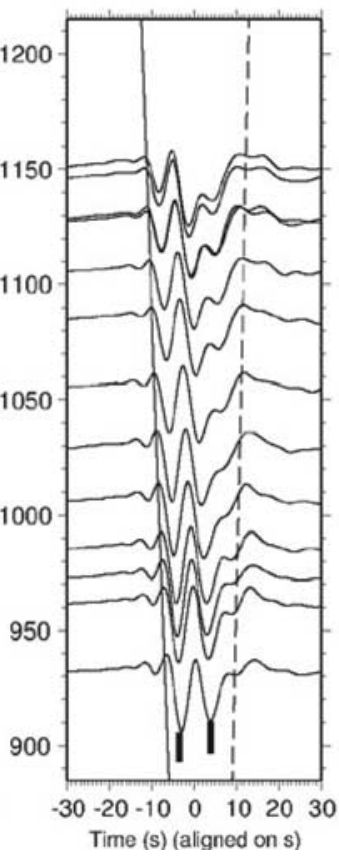

Rad.

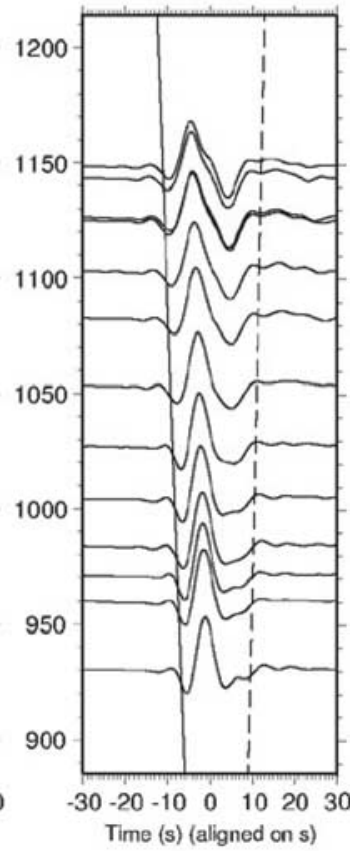

Rad.

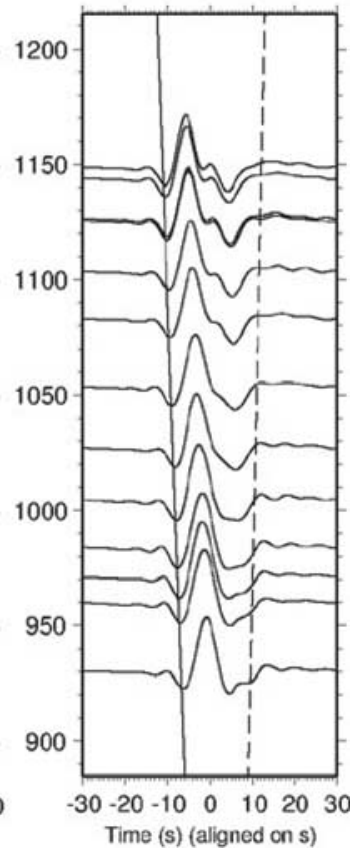

Figure 16. Three-component SEM synthetic waveforms for two different models. (a) Model 2 without a slow mantle wedge but with a LVL. (b) Model 2 with neither a slow mantle wedge nor a LVL. The black bars indicate the upswing phases on the tangential component or the first and secondary arrivals on the vertical component. When there are no slow anomalies (neither a LVL nor a mantle wedge), the amplitude of the first arrival gets bigger compared to the secondary arrival on the vertical component, and the amplitude of the positive later arriving upswings on the tangential component gets smaller.

thickness and $\delta \ln \alpha$, the depth extent of the LVL is well determined and is twice as large as previously observed.

[35] If we assume a $10 \mathrm{~km}$ thick LVL comparable to the low-velocity waveguide observed in previous studies [e.g., Matsuzawa et al., 1986; Abers, 2003], then the $\delta \ln \alpha$ we obtain here is double the $5-8 \%$ seen in other Northern Pacific arcs (Kurile, Alaska, Aleutian, north Japan, and the Marianas). Also, if we assume a LVL with common $\delta \ln \alpha=$ $-7 \%$ in our preferred model, then it is $20 \mathrm{~km}$ thick and is thicker than that obtained by other investigators. For exam- 
(a)

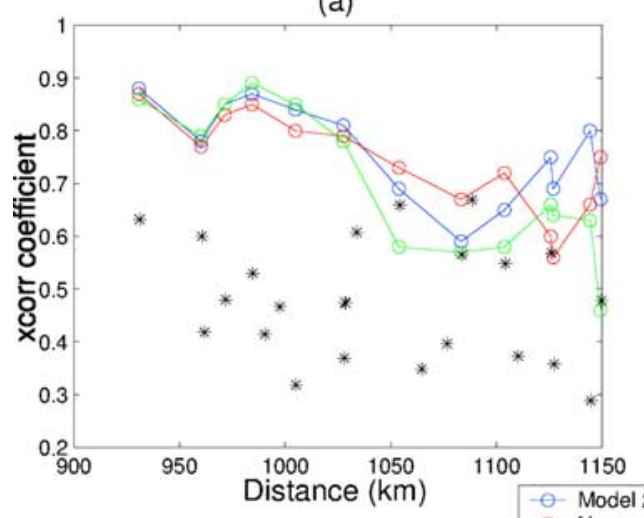

(b)

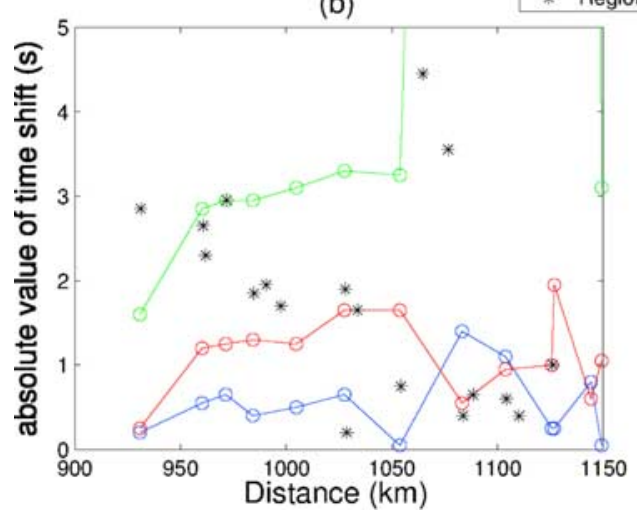

(c)

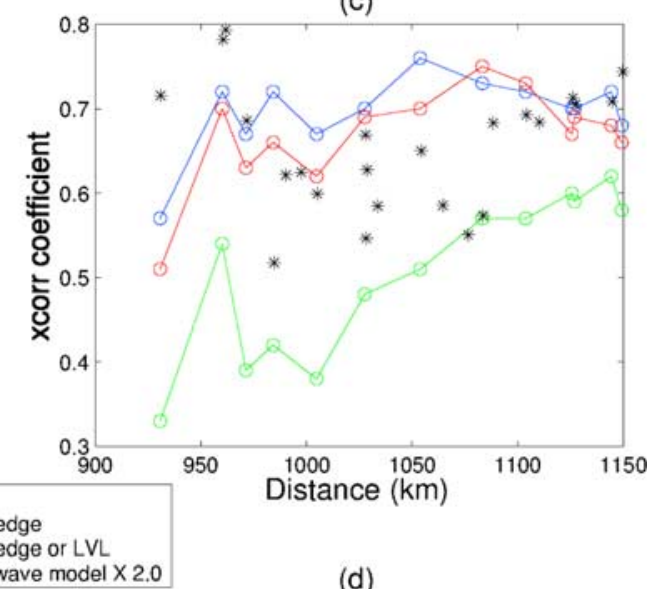

(d)

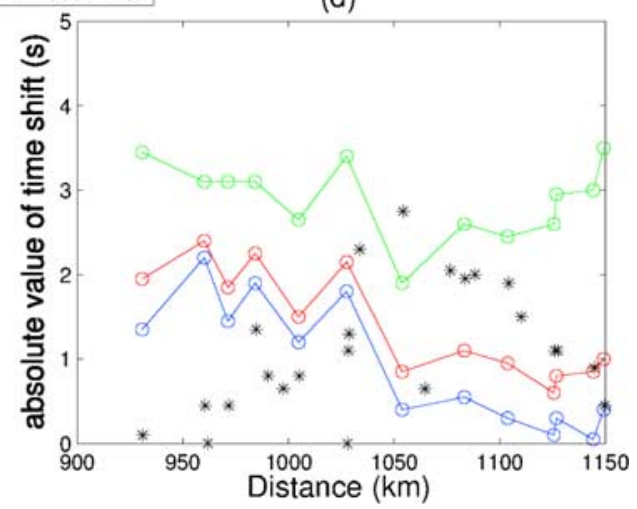

Figure 17. Comparison of (top) cross-correlation coefficients and (bottom) traveltime anomalies between data and SEM synthetics calculated for the regional model (black stars), model 2 (blue circles), model 2 without a slow mantle wedge but with a LVL (red circles), and model 2 with neither a slow mantle wedge nor a LVL (green circles). Stars indicate individual trace cross-correlation results and circles indicate stacked trace cross-correlation results. (a, b) SH waves. (c, d) Vertical S waves.

ple, Matsuzawa et al. [1986] proposed a 5 to $10 \mathrm{~km}$ thick crust from differential traveltime between direct $\mathrm{P}$ and P-toS converted phase. Furumura and Kennett [2005] suggest an $8 \mathrm{~km}$ thick LVL with an $80 \mathrm{~km}$ thick slab from the waveform similarity of simulated wave train to the observation at one single station, KMU. Their study is on the effect of elongated scatterers inside the plate, and is quite a unique approach. In contrast, we used broadband waveform data recorded by a dense array, and find that the later arriving SH upswing is sensitive to both the thickness and $\delta \ln \beta$ inside the LVL. In particular, we found that, with $\delta \ln$ $\alpha=-7 \%$, a LVL less than $10 \mathrm{~km}$ thick cannot explain the upswing phase; this is a very strong constraint.

[36] The LVL atop the slab is often interpreted as descending hydrous mafic oceanic crust (less than $10 \mathrm{~km}$ thick), and these hydrous mafic rocks (e.g., gabbro, greenschist, epidote-blueschist/amphibolite) have lower seismic velocities than normal mantle until they dehydrate completely and convert to anhydrous eclogite. Given the age, convergence rate, and boundary condition of the subducting Pacific plate beneath NE Japan, the depth of complete eclogitization is expected to be $\sim 150 \mathrm{~km}$ [Peacock and Wang, 1999; Hacker et al., 2003a, 2003b].

[37] The LVL we observe here extends to greater depths than the maximum depth of stability for hydrous mafic lithologies. Thus the NE Japan LVL probably is not the subducted oceanic crust (at least, not in the depth range of $150-300 \mathrm{~km}$ ), and instead is more likely serpentinized peridotite, which retains its water to much greater depths [Schmidt and Poli, 1998]. There are two possible locations and origins of serpentine consistent with our observations: (1) a layer of serpentinized peridotite formed in the corner of the mantle wedge, in response to dehydration of oceanic crust at shallow depths [Schmidt and Poli, 1998], and gets dragged down along the top of the descending slab; or, (2) a layer of serpentinized peridotite formed in the lithospheric mantle of the downgoing plate before its subduction, in response to hydrothermal circulation, perhaps related to faulting at the outer rise of the trench [Ranero and Sallares, 2004; Ranero et al., 2005]. These two scenarios are not mutually exclusive. Whether the layer of serpentinized peridotite lies above or below the oceanic crust is not resolved in this study due to tens of kilometers uncertainties in the locations of deep earthquakes and the interface between the slab and mantle wedge.

[38] Nevertheless, our results require that serpentinization of peridotite is the dominant cause of the NE Japan LVL. Serpentinized peridotites, whether serpentine or chlorite dominated, are characterized by very large negative seismic velocity anomalies compared to the normal mantle (i.e., IASPEI91) to depths at least as great as the reactions that transform serpentine and/or chlorite into phase $\mathrm{A}$ and $\mathrm{H}_{2} \mathrm{O}$; 
this reaction should be accompanied by a circa $50 \%$ reduction in the amplitude of the velocity anomaly [Hacker et al., 2003a]. The pressures at which these reactions occur along slab geotherms are poorly known but generally believed to fall between $6 \mathrm{GPa}$ and $8 \mathrm{GPa}(\sim 180-$ $260 \mathrm{~km}$ ). This depth could be significantly greater for relatively cold slab geotherms. On the basis of the extrapolated trend of previously calculated slab geotherms (P-T paths with $\mathrm{P}<5 \mathrm{GPa}$ ) [Peacock and Wang, 1999] for the NE Japan subduction zone, it is plausible that the geotherm associated with the bottom of the oceanic crust is sufficiently cold to intersect the conversion to phase $\mathrm{A}$ at pressures similar to the bottom of the LVL we observed. Conversely, the warmer temperatures in the mantle wedge above the slab should promote conversion of serpentinite to phase A-rich
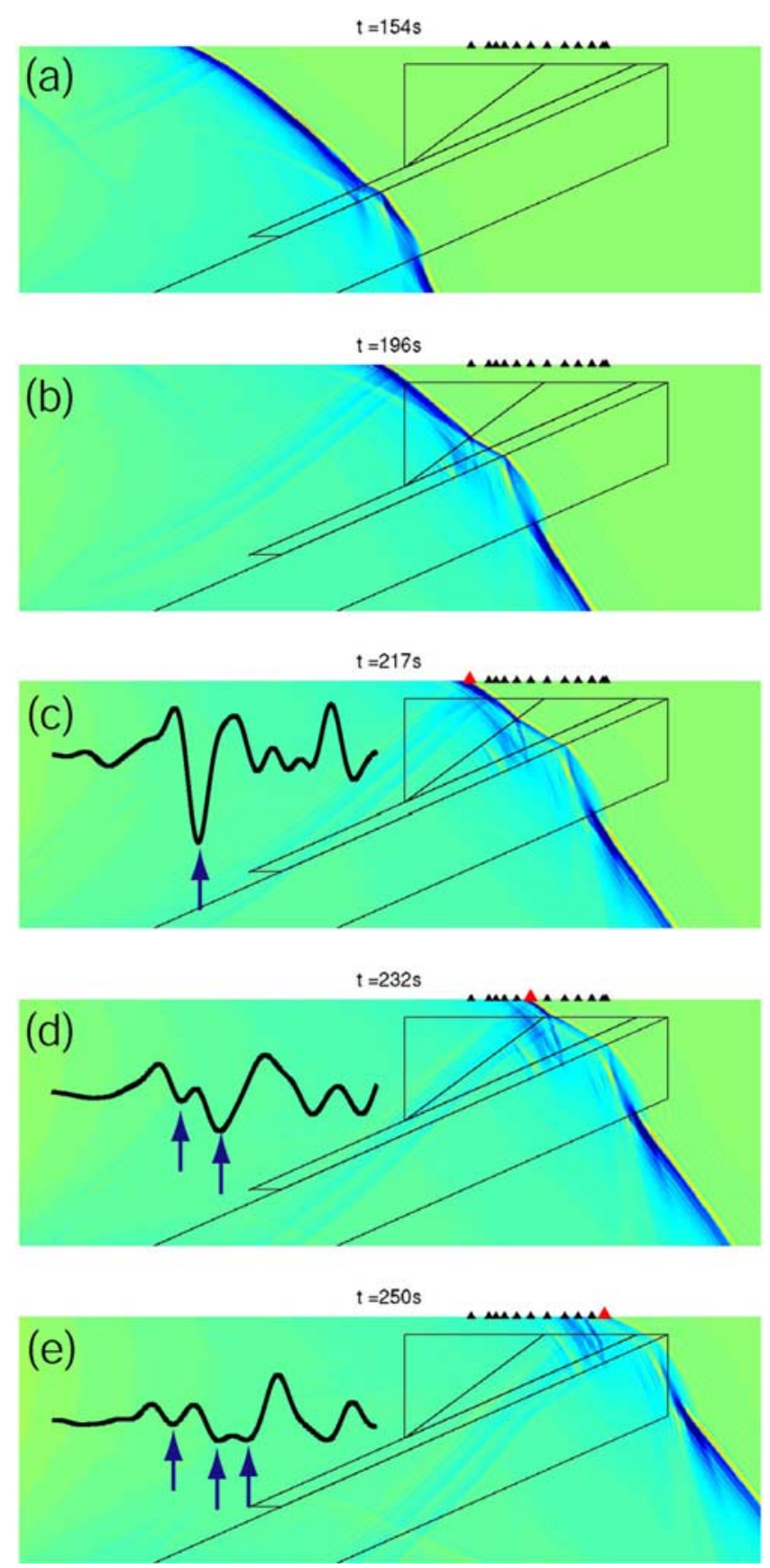

peridotite at lower pressures. Thus these factors lead us to favor the hypothesis that the LVL beneath NE Japan reflects a layer of serpentinite in the oceanic lithosphere, beneath the oceanic crust.

[39] Because fully serpentinized ultramafic mantle is $30 \%$ slower in compressional wave velocity $(\alpha)$ than the normal mantle [Hacker et al., 2003a], a $10 \mathrm{~km}$ thick serpentine layer beneath NE Japan having a $\delta \ln \alpha$ of $-16 \pm 3 \%$ should be $50 \%$ serpentinized $\left(\sim 7\right.$ wt $\left.\% \mathrm{H}_{2} \mathrm{O}\right)$. Such a serpentine content requires that serpentinization took place in an environment with vigorous water supply. We suggest that such large amounts of seawater could have circulated into the interior of the slab beneath the outer rise of the Japan trench by way of extensional faults reaching tens of kilometers below the seafloor [Kobayashi et al., 1998; Kanamori, 1971]. Note, however, that our results are also consistent with a thicker LVL having a lower average percentage of serpentine. Two potential sources of systematic error in the interpretation we present above are the relatively poor constraints on the phase diagram for hydrous peridotite at pressures above $5 \mathrm{GPa}$, and the relatively poor understanding of P-T paths followed by deeply subducted slabs.

\section{Conclusion}

[40] We have generated 2-D and 3-D synthetic seismograms for an existing tomographic model of the subduction zone beneath Japan developed by Zhao et al. [1994]. The synthetics were compared with observations from the Hi-net array involving over 500 stations. The tomographic model reduces the cross-correlation traveltime residuals relative to a 1 -D model by $\sim 50 \%$. However, the waveforms are not well matched. A detailed slab model along a restricted 2-D corridor is constructed by a combination of forward modeling and a grid search. The model confirms that the average

Figure 18. FDM snapshots of $\mathrm{SH}$ wave propagation in model 2. The black triangles indicate the station locations (shown as red circles in Figure 9). The color indicates the amplitude of the displacement field for an $\mathrm{SH}$ source located at a depth of $600 \mathrm{~km}$. Negative displacement is shown in blue, and positive displacement is shown in red. The polygons with a black outline indicate the different regions in model 2. (a) Snapshot at $154 \mathrm{~s}$. Part of the wavefront energy starts to be trapped in the LVL, and the wavefront inside the slab is obviously advanced compared to the wavefront outside the slab. (b) Snapshot at $196 \mathrm{~s}$. The energy in the wavefront is further redistributed to different branches when the wave enters the heterogeneous mantle wedge. (c) Snapshot at 217 s. The waveform recorded by the closest stations shows a single pulse. (d) Snapshot at 232 s. The waveform recorded by intermediate distance stations starts to have a secondary arrival. (e) Snapshot at $250 \mathrm{~s}$. The waveform recorded by the furthest stations shows multiple arrivals. Three distinct data waveforms are shown in the left half of Figures 18c, 18d, and 18e, recorded by stations marked by red triangles. The arrows indicate initial and late (multiple) arrivals. Note that the absolute amplitude decreases for multiple-arrival waveforms compared to single-pulse waveforms, which indicates an energy redistribution between multiple branches of the wavefront. 
compressional wave velocity inside the slab is about $4.5 \%$ higher than the ambient mantle and that the $120 \mathrm{~km}$ thick slab subducts with a dip angle near $24^{\circ}$. The slab sinks into the transition zone and flattens toward the west, with the compressional wave velocity increasing by $3 \%$. The $2-\mathrm{D}$ model indicates there is an elongated low-velocity layer above the slab extending down to a depth of about $300 \mathrm{~km}$, with an $\mathrm{S}$ wave velocity reduction of $14 \%$ compared to the normal mantle if the thickness of the LVL is $20 \mathrm{~km}$. However, the thickness of the LVL trades off to some extent with a low $\mathrm{S}$ wave velocity in the LVL. A model with a LVL on top of the slab and a slow mantle wedge produces the observed strong secondary SH arrivals, which cannot be easily imaged with tomographic techniques.

[41] We also note that the tomographic result depends on the initial slab structure. No tomographic study with an initial slab structure having an embedded LVL has been attempted. It is possible that adding a $20 \mathrm{~km}$ thick LVL in the initial model of inversion can yield a structure equally consistent with the traveltime data used in the previous inversion studies. We did not include attenuation in the waveform modeling, which could have caused overestimation of the thickness or $\delta \ln \alpha$; what we present here is the upper limit of these two parameters. In summary we believe that the question of how extensive the low-velocity layer is has not been resolved yet, and it would be an interesting future project to examine the broadband waveform data for many more events in the way we did in this paper.

[42] We interpret the LVL beneath NE Japan to be composed of hydrated mafic and/or ultramafic rocks: above a depth of $150 \mathrm{~km}$, the LVL could be composed of hydrous mafic crust and serpentinized peridotite above and/or below the descending crust; below a depth of $150 \mathrm{~km}$ this hydrous layer could be more likely composed of serpentinized peridotite (or, at the greatest depths, phase A) above and/ or below the fully eclogitized oceanic crust. Water released from the dehydration reactions in this hydrous zone could cause the abundant arc volcanism, the intermediate-depth intraslab seismicity $(70-300 \mathrm{~km})$ [Hacker et al., 2003b; Ranero et al., 2005], and possible silent slip events, which have been observed in other subduction zones (e.g., Cascadia and the Tokai region in central Japan) [Dragert et al., 2001; Ozawa et al., 2002].

[43] Acknowledgments. We thank the Hi-net Data Center, especially Mizuho Ishida and Masako Sakanashi, for their help in providing the waveform data. We also thank John Eiler for constructive discussions and helpful comments on mineral physics. We also thank two reviewers and the Associate Editor Jeroen Ritsema for help in improving the manuscript. This research was supported by the National Science Foundation under grant EAR-0309576. This is contribution 9137 of the Division of Geological and Planetary Sciences (GPS), California Institute of Technology. This is contribution 36 of Caltech's Tectonic Observatory. The numerical simulations for this research were performed on the GPS Dell cluster.

\section{References}

Abers, G. (2003), Hydrated subducted crust at 100-250 km depth, Earth Planet. Sci. Lett., 176, 323-330.

Cormier, V. F. (1989), Slab diffraction of $S$ waves, J. Geophys. Res., 94, $3006-3024$

Dragert, H., K. Wang, and T. S. James (2001), A silent slip event on the deeper Cascadia subduction interface, Science, 292, 1525-1528.

Fukao, Y., S. Hori, and M. Ukawa (1983), A seismological constraint on the depth of basalt-eclogite transition in a subducting oceanic crust, Nature, $303,413-415$.
Furumura, T., and B. L. N. Kennett (2005), Subduction zone guided waves and heterogeneity structure of the subducted plate: Intensity anomalies in northern Japan, J. Geophys. Res., 110, B10302, doi:10.1029/ 2004JB003486.

Hacker, B. R., G. Abers, and S. Peacock (2003a), Subduction factory: 1. Theoretical mineralogy, densities, seismic wave speeds and $\mathrm{H}_{2} \mathrm{O}$ contents, J. Geophys. Res., 108(B1), 2029, doi:10.1029/2001JB001127.

Hacker, B. R., S. M. Peacock, G. A. Abers, and S. D. Holloway (2003b), Subduction factory: 2. Are intermediate-depth earthquakes in subducting slabs linked to metamorphic dehydration reactions?, J. Geophys. Res., 108(B1), 2030, doi:10.1029/2001JB001129.

Helmberger, D. V., and J. E. Vidale (1988), Modeling strong motions produced by earthquakes with two-dimensional numerical codes, Bull. Seismol. Soc. Am., 78, 109-121.

Hori, S. (1990), Seismic wave guided by untransformed oceanic crust subducting into the mantle: The case of the Kanto district, central Japan, Tectonophysics, 176, 355-376.

Igel, H., T. Nissen-Meyer, and G. Jahnke (2002), Wave propagation in 3D spherical sections: Effects of subduction zones, Phys. Earth Planet. Inter, $132,219-234$.

Kanamori, H. (1971), Seismological evidence for a lithospheric normal faulting-The Sanriku earthquake of 1933, Phys. Earth. Planet. Inter., 4, 289-300.

Kennett, B. L. N., and E. R. Engdahl (1991), Traveltimes for global earthquake location and phase identification, Geophys. J. Int., 105, 429-465.

Kobayashi, K., M. Nakanishi, K. Tamaki, and Y. Ogawa (1998), Outer slope faulting associated with the western Kuril and Japan trenches, Geophys. J. Int., 134, 356-372.

Komatitsch, D., and J. Tromp (2002a), Spectral-element simulations of global seismic wave propagation-I. Validation, Geophys. J. Int., 149, $390-412$.

Komatitsch, D., and J. Tromp (2002b), Spectral-element simulations of global seismic wave propagation-II. 3-D models, oceans, rotation, and self-gravitation, Geophys. J. Int., 150, 303-318.

Martin, S., A. Rietbrock, C. Haberland, and G. Asch (2003), Guided waves propagating in subducted oceanic crust, J. Geophys. Res., 108(B11), 2536, doi:10.1029/2003JB002450.

Martin, S., C. Haberland, and A. Rietbrock (2005), Forearc decoupling of guided waves in the Chile-Peru subduction zone, Geophys. Res. Lett., 32, L23309, doi:10.1029/2005GL024183.

Matsuzawa, T., N. Umino, A. Hasegawa, and A. Takagi (1986), Upper mantle velocity structure estimated from PS-converted wave beneath the north-eastern Japan arc, Geophys. J. R. Astron. Soc., 86, 767-787.

Ozawa, S., M. Murakami, M. Kaidzu, T. Tada, T. Sagiya, Y. Hatanaka, H. Yarai, and T. Nishimura (2002), Detection and monitoring of ongoing aseismic slip in the Tokai region, central Japan, Science, 298, 1009-1012.

Peacock, S. M., and K. Wang (1999), Seismic consequences of warm versus cool subduction metamorphism: Examples from southwest and northeast Japan, Science, 286, 937-939.

Ranero, C. R., and V. Sallarès (2004), Geophysical evidence for hydration of the crust and mantle of the nazca plate during bending at the North Chile trench, Geology, 32, 549-552.

Ranero, C. R., A. Villaseñor, J. P. Morgan, and W. Weinrebe (2005), Relationship between bend-faulting at trenches and intermediate-depth seismicity, Geochem. Geophys. Geosyst., 6, Q12002, doi:10.1029/ 2005GC000997.

Schmidt, M. W., and S. Poli (1998), Experimentally based water budgets for dehydrating slabs and consequencies for arc magma generation, Earth Planet. Sci. Lett., 163, 361-379.

Vidale, J. E. (1987), Waveform effects of a high-velocity, subducted slab, Geophys. Res. Lett., 14, 542-545.

Vidale, J. E., and D. Garcia-Gonzalez (1988), Seismic observation of a highvelocity slab $1200-1600 \mathrm{~km}$ in depth, Geophys. Res. Lett., 15, 369-372.

Vidale, J. E., D. V. Helmberger, and R. W. Clayton (1985), Finite-difference seismograms for SH waves, Bull. Seismol. Soc. Am., 75, 1765-1782.

Zhao, D. (2001), Seismic structure and origin of hotspots and mantle plumes, Earth Planet. Sci. Lett., 192, 251-265.

Zhao, D., and A. Hasegawa (1993), $P$ wave tomographic imaging of the crust and upper mantle beneath the Japan islands, J. Geophys. Res., 98, $4333-4353$

Zhao, D., A. Hasegawa, and H. Kanamori (1994), Deep structure of Japan subduction zone as derived from local regional, and teleseismic events, J. Geophys. Res., 99, 22,313-22,329.

Zhou, H., and G. Chen (1995), Waveform response to the morphology of 2-D subducted slabs, Geophys. J. Int., 121, 511-522.

M. Chen, D. Helmberger, H. Kanamori, and J. Tromp, Seismological Laboratory, California Institute of Technology, 1200 E. California Blvd., Pasadena, CA 91125, USA. (mchen@gps.caltech.edu) 